Review Article

\title{
Recent Pathophysiological Aspects of Peyronie's Disease: Role of Free Radicals, Rationale, and Therapeutic Implications for Antioxidant Treatment-Literature Review
}

\author{
Gianni Paulis, ${ }^{1,2}$ Gennaro Romano, ${ }^{3}$ Luca Paulis, ${ }^{4}$ and Davide Barletta ${ }^{5}$ \\ ${ }^{1}$ Regina Apostolorum Hospital, Andrology Center, Albano Laziale, Rome, Italy \\ ${ }^{2}$ Castelfidardo Medical Team, Peyronie's Disease Care Center, Rome, Italy \\ ${ }^{3}$ Italian League against Cancer, Department of Urologic Oncology, Section of Avellino, Avellino, Italy \\ ${ }^{4}$ Faculty of Pharmacy, University of Rome "La Sapienza", Rome, Italy \\ ${ }^{5}$ Department of Urology, Andrology Center, San Matteo Hospital, Pavia, Italy \\ Correspondence should be addressed to Gianni Paulis; paulisg@libero.it
}

Received 15 March 2017; Accepted 30 May 2017; Published 4 July 2017

Academic Editor: Matthew Rutman

Copyright (C) 2017 Gianni Paulis et al. This is an open access article distributed under the Creative Commons Attribution License, which permits unrestricted use, distribution, and reproduction in any medium, provided the original work is properly cited.

\begin{abstract}
Peyronie's disease (PD) is a chronic inflammation of tunica albuginea of the corpora cavernosa that causes an inelastic plaque resulting in penis deformation. Although its etiology is not completely known, there is general consensus that PD is genetically transmitted and secondary to penile trauma. In recent years, numerous studies demonstrated the role played by oxidative stress in PD pathogenesis, and other studies have described successful use of antioxidants in PD treatment. Oxidative stress is an integral part of this disease, influencing its progression. In the early stages of PD, the inflammatory infiltrate cells produce high quantities of free radicals and proinflammatory and profibrotic cytokines, with consequent activation of transcription factor NF- $\kappa$ B. While conservative therapies commonly used in the early stages of PD include oral substances (Potaba, tamoxifen, colchicine, and vitamin E), intralesional treatment (verapamil, interferon, steroids, and more recently collagenase clostridium histolyticum-Xiaflex), and local physical treatment (iontophoresis, extracorporeal shock wave therapy, and penile extender), the significant results obtained by emerging treatments with the antioxidants cited in this article suggest these therapeutic agents interfere at several levels with the disease's pathogenetic mechanisms. Antioxidants therapy outcomes are interesting for good clinical practice and also confirm the fundamental role played by oxidative stress in PD.
\end{abstract}

\section{Introduction}

Peyronie's disease (PD), a chronic inflammation of the tunica albuginea of the corpora cavernosa, causes formation of a hard, inelastic plaque, often resulting in penis deformation. Prevalence varies between $3.2 \%$ and $13 \%$; it generally affects males around 50 years of age, but recently a rise in frequency has been recorded in younger patients $[1,2]$. Like Dupuytren's contracture, PD more frequently affects white men, more rarely black, and Asian men [3]. Although its etiology is not completely known, there is general consensus that PD is genetically transmitted and secondary to penile trauma $[4,5]$. Familiar aggregation and genetic transmission through HLAB7 antigens had been amply described and understood [68]. Recently, a genetic locus that PD shares with Dupuytren's contracture was identified; WNT2 is the locus involved in genetic predisposition for both Dupuytren's disease and PD [9]. Previously, some studies had already observed the analogy and strong affinity between the two diseases: Dupuytren's contracture's typical cells with "cross-banded" nuclei had been observed in PD plaques in 1976; in 1989, Somers et al., after histological examination of PD plaques, proved an increase in type III collagen content, similarly to what occurs in Dupuytren's contracture $[10,11]$.

PD symptoms include penile pain $(20 \%-70 \%$ of cases), penile curvature or deformation ( $94 \%$ of cases), erectile dysfunction (31.5\% of cases), depressive state ( $48 \%$ of cases), and presence of a more or less palpable penile nodule [12-14]. Penile distortion occurs because the area of disease (plaque) has a tendency to gradually become less elastic; histological 
analysis of penile plaques unfailingly detects an alteration and disorganization of collagen associated with a reduction in elastin density [15].

The disease has three stages: acute posttraumatic period $>$ inflammatory remodeling phase $>$ stabilization phase.

The first stage of the disease is characterized by a brief acute posttraumatic period, lasting about 2 weeks, during which, after blood extravasation and fibrin and platelet accumulation, powerful recruitment of inflammatory cells, macrophages, and lymphocytes occurs [16]. During this brief period, no penile nodule is palpable and no plaque is visible on ultrasound. The next stage which lasts about 12-18 months is the inflammatory remodeling phase $[16,17]$. In this stage various growth factors start to be produced, initially causing tissue degradation, production of a new extracellular matrix (ECM), and tissue remodeling; in this stage, rapid growth of plaque occurs, often associated with pain and penile curvature; the plaque then tends to gradually consolidate and become increasingly more fibrous, until one or more areas of calcification, which tend to grow larger, make their appearance. Pain (when present) then usually disappears, but an increase in curvature angle is almost always observed. At the end of this inflammatory phase, the disease stabilizes. In this third phase (stabilization), pain is typically absent, penis deformation is stable, and fibrocalcification of the plaque is practically complete; consequently, nodules are always clearly palpable in this phase.

1.1. Premises of Microscopic and Functional Anatomy. The tunica albuginea of the corpora cavernosa is made up of both collagen fibers (the majority) and elastic fibers. Whereas collagen fibers have greater resistance to traction and are inelastic, elastic fibers can be extended up to $150 \%$ of their normal length [18]. With no elastic fibers in the tunica albuginea, the penis would not be able to grow in length and size during erection. In normal conditions and in the absence of disease, the elastic fibers along the penile shaft, within the tunica albuginea, appear as a net interwoven with collagen fibers. However, in the penile crura and distal part of the corpora cavernosa (apex), the tunica albuginea is only or almost exclusively made up of collagen fibers [18, 19]. Thus, any local change in elastic fiber content can cause penile deformation.

The purpose of this article is to clarify and explain the significant role of the oxidative stress in PD pathogenesis; the other important objective of the article is to explain the resulting role of antioxidants in PD treatment.

\section{Pathophysiology of Peyronie's' Disease (Figure 1)}

2.1. Mechanism of Plaque Formation. Following trauma, delamination of the tunica albuginea occurs, with extravasation and accumulation of fibrin between the layers, due to insufficient activation of fibrinolysis [6]. Presence of the platelet thrombus and fibrin is responsible for the subsequent cascade of events. Fibrin acts as a strong chemotactic factor, recruiting inflammatory cells like neutrophil granulocytes, macrophages, mast cells, and so forth [20]. These cells immediately begin to produce proinflammatory cytokines, particularly transforming-growth-factor-beta-1 (TGF-ß1); platelets, too, along with the macrophages already present in the area after the posttraumatic extravasation, release TGF- 31 cytokines and platelet-derived-growth-factor (PDGF) [17, 21]. Fibrin accumulation also promotes the influx of fibroblasts, already attracted by TGF- $ß 1$ and PDGF [20, 21]. Macrophages and inflammatory cells are also responsible for the production of elastase, an enzyme that can cause degradation of the tunica albuginea's elastic fibers [20, 22]. Enhanced elastase activity and elastin-derived peptides act chemotactically, contributing to both the increase in the inflammatory cellular infiltrate and the influx of fibroblasts $[20]$.

\subsection{Role of the Disease's Most Important Biological Mediators}

2.2.1. Transforming-Growth-Factor-Beta-1 (TGF- $\beta 1)$. TGF$ß 1$, produced by platelets, macrophages, neutrophils, and $\mathrm{T}$ lymphocytes, is considered the most important profibrotic factor associated with PD.

TGF- 11 possesses chemotactic activity on blood neutrophils, monocytes, lymphocytes, and fibroblasts $[6,17$, 22-24]. TGF-ß1 activity includes the following: inducing fibroblasts to produce collagen; influencing ECM deposition, stimulating synthesis of individual components of the matrix, such as proteoglycans and fibronectin; promoting fibroblast proliferation and differentiation into myofibroblasts, that is, mesenchymal cells that share the same phenotype as smooth muscle cells and fibroblasts and therefore have the capacity both to contract and to synthesize collagen [6, 22, 23, 25]. In addition, TGF- $\$ 1$ has the following actions: induces reactive oxygen species (ROS) production; inhibits production of certain matrix metalloproteinases (MMPs), particularly MMP1, MMP-8, and MMP-13, which have collagenolytic activity, increasing synthesis of tissue inhibitors of matrix metalloproteinase (TIMPs, specifically TIMP-1); increases synthesis of MMP-10, which can degrade elastin; activates the nuclear factor kappa-light-chain-enhancer of activated B cells (NF$\kappa \mathrm{B})$; inhibits fibrinolysis by inducing synthesis of plasminogen activator inhibitor-1 (PAI-1); induces osteogenesis [17, 22, 2632]. However, it has been shown that during the progression of disease the plaque undergoes calcification or ossification in $15 \%-25 \%$ of PD cases [32].

2.2.2. Platelet-Derived Growth Factor (PDGF). Produced mainly by platelets, but even by macrophages, PDGF, too, is profibrotic. Like TGF- 31 , PDGF has chemotactic activity on fibroblasts [6]. Furthermore, PDGF induces TIMP-1 synthesis, collagen biosynthesis, fibroblast proliferation, and differentiation into myofibroblasts, and it contributes to plaque calcification and ossification, also recruiting osteoblasts $[6,21$, $22,26,33,34]$.

2.2.3. Interleukin (IL-1). Proinflammatory cytokine IL-1 is produced by macrophages and fibroblasts [35, 36]. One of PD's numerous profibrotic factors is that it is strongly chemotactic for fibroblasts; it stimulates collagen synthesis; 


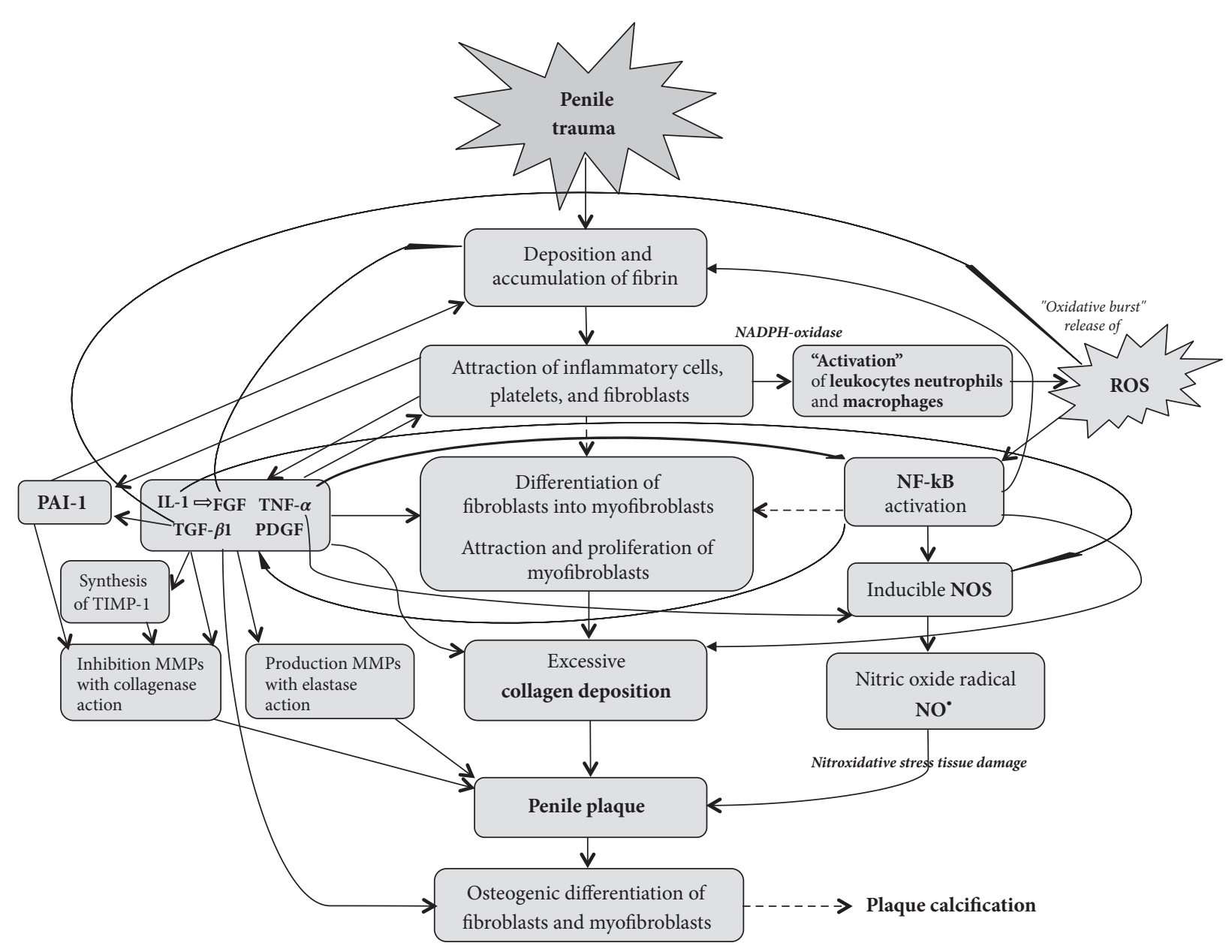

FIgURE 1: Pathogenetic mechanisms of Peyronie's disease.

it increases fibroblast production of MMP-1, MMP-2, MMP8, MMP-9, MMP-10, and MMP-13; it promotes synthesis of MMP-9 and MMP-3 and basic fibroblast growth factor; it stimulates production of inducible nitric oxide synthase (iNOS), an enzyme that plays a fundamental role in oxidative stress; it activates NF- $\kappa \mathrm{B}[6,12,17,34,35,37,38]$.

2.2.4. Basic Fibroblast Growth Factor (bFGF). This typically profibrotic growth factor is mainly produced by fibroblasts and myofibroblasts; it attracts fibroblasts in the area and induces their proliferation, stimulates collagen synthesis, increases synthesis of MMP-1 and MMP-9 (with elastic activity) and TIMP-1, and causes further local fibrin deposit $[6,33,34,37]$.

\subsubsection{Plasminogen Activator Inhibitor-1 (PAI-1). Another} important profibrotic factor produced mainly by platelets is that PAI-1 inhibits fibrinolysis, causing fibrin to remain at the site, triggering recruitment of inflammatory cells and subsequent release of profibrotic factors (cytokines, etc.); it also hinders collagenolysis and inhibits MMPs $[39,40]$.

2.2.6. Tumor Necrosis Factor (TNF- $\alpha$ ). Produced by monocytes and macrophages, in the course of the disease its activity involves the following: recruiting fibroblasts and stimulating their proliferation; stimulating iNOS production; inducing cellular apoptosis; stimulating production of MMP9 (elastase); activating nuclear factor NF- $\kappa$ B; inducing PAI-1 synthesis [6, 34, 37, 41-43].

In $\mathrm{PD}$, therefore, we have a preponderance of profibrotic factors causing excessive deposition of collagen and ECM; this leads to extreme disorganization of the collagen fibers, loss of elastic fibers, and consequent elasticity loss in the tissues involved. Although both type I collagen and type III collagen have been shown to be present in PD, the latter is much more plentiful in PD plaque [11, 30]. Microscopic studies have shown that besides an increased number of fibroblasts, a haphazard arrangement is present, with random orientation of collagen bands and a marked reduction in elastic fibers, which appear disrupted, with excessive accumulation of elastin [20]. Consequently, a thickening of the tissue (plaque) forms, resulting in elasticity loss and inevitable onset of penile deformation.

2.3. Free Radicals and Oxidative and Nitrosative Stress as Fundamental Component of Peyronie's Disease. In the last fifteen years, oxidative stress has been shown to play a decisive 
TABLE 1: Chemical reactions during oxidative stress and direct reactions of vitamin E and coenzyme Q10 with reactive species.

\begin{tabular}{|c|c|}
\hline Superoxide anion $\left(\mathrm{O}_{2}{ }^{--}\right)$ & $\mathrm{NADPH}+\mathrm{O}_{2} \rightarrow \mathrm{NADP}^{+}+\mathrm{H}^{+}+\mathrm{O}_{2}^{\cdot-}$ \\
\hline \multirow{2}{*}{ Hydrogen peroxide $\left(\mathrm{H}_{2} \mathrm{O}_{2}\right)$} & SOD \\
\hline & $2 \mathrm{H}^{+}+2 \mathrm{O}_{2}^{\cdot-} \rightarrow \mathrm{O}_{2}+\mathrm{H}_{2} \mathrm{O}_{2}$ \\
\hline Hydroxyl radical (HO•) & $\begin{array}{c}\mathrm{Fe}^{2+}+\mathrm{H}_{2} \mathrm{O}_{2} \rightarrow \mathrm{Fe}^{3+}+\mathrm{HO}^{-}+\mathrm{HO}^{\circ} \\
\text { (Fenton's reaction) }\end{array}$ \\
\hline Hydroxyl radical (HO^) & $\begin{aligned} \mathrm{O}_{2}^{\cdot-}+ & \mathrm{H}_{2} \mathrm{O}_{2} \rightarrow \mathrm{O}_{2}+\mathrm{HO}^{-}+\mathrm{HO}^{\bullet} \\
& (\text { Haber-Weiss reaction })\end{aligned}$ \\
\hline \multirow{2}{*}{ Hypochlorous acid (HOCl) } & MPO \\
\hline & $\mathrm{Cl}^{-}+\mathrm{H}_{2} \mathrm{O}_{2} \rightarrow \mathrm{HO}^{-}+\mathrm{HOCl}$ \\
\hline Singlet oxygen $\left({ }^{1} \mathrm{O}_{2}{ }^{*}\right)$ & $\mathrm{H}_{2} \mathrm{O}_{2}+\mathrm{HOCl} \rightarrow \mathrm{H}_{2} \mathrm{O}+\mathrm{Cl}^{-}+{ }^{1} \mathrm{O}_{2}^{\cdot}$ \\
\hline \multirow{2}{*}{ Nitric oxide $\left(\mathrm{NO}^{\bullet}\right)$} & NOS \\
\hline & L-Arginine $+\mathrm{NADPH}+\mathrm{O}_{2} \rightarrow$ L-Citrulline $+\mathrm{NO}^{\bullet}$ \\
\hline Peroxynitrite $\left(\mathrm{ONOO}^{-}\right)$ & $\mathrm{O}_{2}^{\cdot-}+\mathrm{NO}^{\bullet} \rightarrow \mathrm{ONOO}^{-}$ \\
\hline Peroxynitrous acid (HOONO) & $\mathrm{ONOO}^{-}+\mathrm{H}^{+} \rightarrow \mathrm{HOONO}$ \\
\hline Hydroxyl radical $\left(\mathrm{HO}^{\circ}\right)$ and nitrogen dioxide radical $\left(\mathrm{NO}_{2}{ }^{\circ}\right)$ & $\mathrm{HOONO} \rightarrow \mathrm{HO}^{\bullet}+\mathrm{NO}_{2}^{\bullet}$ \\
\hline \multirow{3}{*}{ Antioxidant activity of vitamin $E$ ( $\alpha$-tocopherol-OH) } & $\mathrm{R}^{\bullet}$ (reactive species) $+\alpha$-tocopherol-OH $\rightarrow \mathrm{RH}+\alpha$-tocopherol- $\mathrm{O}^{\bullet}$ \\
\hline & $\mathrm{HO}^{\bullet}$ (hydroxyl radical) $+\alpha$-tocopherol-OH $\rightarrow \mathrm{H}_{2} \mathrm{O}+\alpha$-tocopherol- $\mathrm{O}^{\bullet}$ \\
\hline & $\mathrm{LOO}^{\bullet}+\alpha$-tocopherol-OH $\rightarrow \mathrm{LOOH}+\alpha$-tocopherol-O${ }^{\bullet}$ \\
\hline Antioxidant activity of coenzyme Q10 & $\mathrm{Q} 10 \mathrm{H} 2+\mathrm{LOO}^{\bullet} \rightarrow{\mathrm{Q} 10^{-}}^{-}+\mathrm{H}^{+}+\mathrm{LOOH}$ \\
\hline
\end{tabular}

role in the physiopathological mechanisms of $\mathrm{PD}[6,22,26$, $30,32,34,35,39]$.

At the disease site, ROS hyperproduction occurs in addition to cytokine production. The oxidative stress process begins very early, in the first 24-48 hours: through fibrin's chemotactic activity, an inflammatory cellular infiltrate is produced. Oxidation is truly triggered at this stage of the disease [30]. After leukocyte activation, neutrophil granulocytes and macrophages at the inflammatory site undergo degranulation and release lysosomal enzymes (collagenase, elastase, etc.); at the same time, a "respiratory burst" (or oxidative burst) occurs, which consists in rapid release of ROS (specifically, superoxide radicals and hydrogen peroxide) by neutrophils and macrophages [22]. The activation mechanism is supported by intracellular enzyme nicotinamide adenine dinucleotide phosphate (NADPH) oxidase, present in neutrophils, eosinophils, and macrophages. NADPH-oxidase catalyzes electron transfer from the cytoplasmic NADPH donor to molecular oxygen (acceptor), forming superoxide anion $\left(\mathrm{O}_{2}{ }^{--}\right)$(Table 1). The inflammatory cells then produce high quantities of $\mathrm{O}_{2}{ }^{--}$that is dismutated to hydrogen peroxide $\left(\mathrm{H}_{2} \mathrm{O}_{2}\right)$ thanks to the presence of the superoxide dismutase (SOD) enzyme (Table 1). SOD, a part of the endogenous antioxidant defense system, then intervenes as primary cellular defense against $\mathrm{O}_{2}{ }^{--}$, causing catalytic removal of the superoxide radical. Extracellular SOD plays an essential role in maintaining the redox state, blocking negative local effects of $\mathrm{O}_{2}{ }^{--}$. The superoxide anion also has a direct vasoconstrictive effect through mobilization of calcium ions and can therefore cause erectile dysfunction [44]. The existence of $\mathrm{H}_{2} \mathrm{O}_{2}$ produced via $\mathrm{SOD}$, and simultaneous presence of metal cations such as iron $\left(\mathrm{Fe}^{2+}\right)$, causes Fenton's reaction, which produces another highly toxic reactive species, the hydroxyl radical $\left(\mathrm{HO}^{\circ}\right)$ (Table 1 ). However, $\mathrm{H}_{2} \mathrm{O}_{2}$ can also react with
$\mathrm{O}_{2}{ }^{--}$through the Haber-Weiss reaction to produce $\mathrm{HO}^{\bullet}$ (Table 1). $\mathrm{H}_{2} \mathrm{O}_{2}$ may also be transformed into hypochlorous acid $(\mathrm{HOCl})$, given the presence of myeloperoxidase (MPO) in neutrophils and macrophages (Table 1). Subsequently, $\mathrm{HOCl}$ and $\mathrm{H}_{2} \mathrm{O}_{2}$ react to form singlet oxygen $\left({ }^{1} \mathrm{O}_{2}{ }^{\circ}\right)$, another highly toxic reactive species (Table 1 ). Production of large amounts of proinflammatory cytokines and ROS hyperproduction cause $\mathrm{NF}-\kappa \mathrm{B}$ activation, a central event in the inflammatory response and further production of inflammatory cytokines $[34,35,38]$. NF- $\kappa \mathrm{B}$, present in almost all cell types is a protein complex controlling DNA transcription; in $\mathrm{PD}$, it regulates the expression of genes encoding for FGF, TGF-ß1, iNOS, fibrin, collagen, and so forth [30]. In the course of PD, the iNOS enzyme is mainly produced by macrophages, smooth muscle cells, and myofibroblasts [22]. Induction of an upregulation of iNOS therefore produces high local levels of nitric oxide and a series of its metabolites called reactive nitrogen species (RNS), which are free radicals like ROS but can cause greater cell and tissue damage [34]. In normal conditions, nitric oxide (NO) is the main mediator of penile erection and acts as a nonadrenergic and noncholinergic neurotransmitter, causing release of the smooth muscles of the corpora cavernosa. NO was also known as endothelium-derived relaxing factor (EDRF), and long-standing widespread prejudice held that EDRF could not be identified with unconventional gaseous molecule NO [45]. The chemical reaction producing NO occurs thanks to the presence of amino acid L-arginine via nitric oxide synthase (NOS) activity and leads to final synthesis of L-citrulline and NO (Table 1). The chemical process requires molecular oxygen and proceeds via synthesis of an intermediate, $\mathrm{N} \omega$ hydroxyarginine [46]. Furthermore, the presence of certain cofactors is necessary: NADPH, flavin adenine dinucleotide (FAD), flavin mononucleotide (FMN), tetrahydrobiopterin $\left(\mathrm{BH}_{4}\right)$, and calmodulin (CaM) [34]. Whereas in normal 
conditions penile erection is mediated by the action of the two "constitutive" enzyme forms, neuronal (nNOS) and endothelial NOS (eNOS), which cause normal NO amounts to be produced, in pathological conditions and in PD high local nitric oxide radical $\left(\mathrm{NO}^{--}\right)$concentrations occur, due to mediation of the inducible enzyme form (iNOS) [34]. While isoforms eNOS and nNOS are $\mathrm{Ca}^{2+}$ - and calmodulindependent, iNOS is $\mathrm{Ca}^{2+}$ - and calmodulin-independent and can be induced by inflammatory cytokines. $\mathrm{NO}^{--}$is synthesized by monocytes, macrophages, and fibroblasts. $\mathrm{NO}^{\circ-}$ production from iNOS activity is 100 to 1,000 times greater and has longer duration than $\mathrm{NO}^{\circ-}$ production from nNOS or eNOS [34]. It must be stressed that the effects of nitric oxide radical $\left(\mathrm{NO}^{--}\right)$depend on its concentration, so when local $\mathrm{NO}^{--}$levels increase significantly (as in PD) a high oxidation state is produced. In these conditions, $\mathrm{NO}^{--}$starts to compete with SOD, removing superoxide anion $\left(\mathrm{O}_{2}{ }^{-}\right)$and causing the formation of peroxynitrite (Table 1) [37]. Therefore, synthesis of peroxynitrite depends on the balance between $\mathrm{O}_{2}{ }^{--}$and SOD production and NO synthesis/consumption [34]. Peroxynitrite is a highly toxic, reactive molecule, which can cause cell damage (by lipid peroxidation and DNA fragmentation), tissue damage depletion of plasmatic antioxidants, endothelial smooth muscle relaxation impairment, vascular tone change, and organ dysfunction [34]. When peroxynitrite is protonated, peroxynitrous acid (HOONO) forms, another highly toxic reactive molecule which rapidly breaks down into hydroxyl radical $\left(\mathrm{HO}^{\circ}\right)$ and nitrogen dioxide radical $\left(\mathrm{NO}_{2}{ }^{\circ}\right)$, two other highly reactive cytotoxic molecules (Table 1). During the inflammatory process, some of these reactive species, such as $\mathrm{HO}^{\circ}$, can chemically react with lipids (lipid peroxidation) generating radicals, for example, lipid alkyl radical $\left(\mathrm{L}^{\circ}\right)$, lipid alkoxyl radical $\left(\mathrm{LO}^{\circ}\right)$, and lipid peroxyl radical ( $\left.\mathrm{LOO}^{\circ}\right)$; these toxic substances can also react with $\mathrm{NO}^{--}$producing less reactive substances (lipid nitrite/LONO, lipid peroxynitrite/LOONO) which can play a role as diagnostic indicators of lipid peroxidation [30].

\subsection{Mechanisms of Action of Antioxidants Used in the Treat- ment of Peyronie's Disease (Table 2)}

2.4.1. Vitamin E. This liposoluble substance was first suggested for PD treatment in 1948 by Scott and Scardino [47]. It has many properties. Antioxidant properties: vitamin $\mathrm{E}$ generally reacts with reactive species $\left(\mathrm{R}^{\circ}\right)$, but its best-known reaction is with hydroxyl radical $\left(\mathrm{HO}^{\circ}\right)$, with donation of a hydrogen ion $\left(\mathrm{H}^{+}\right)$and formation of a stable, no longer reactive molecule (hydrogen peroxide) [30]. Furthermore, when vitamin $\mathrm{E}$ reacts with lipid peroxyl radical, it leads to formation of a tocopheroxyl radical, a relatively stable, poorly reactive molecule that does not cause a new lipid peroxidation process (Table 1); the tocopheroxyl radical soon reacts with any available $\mathrm{H}^{+}$molecule, going back to the stable form of vitamin E ( $\alpha$-tocopherol-OH). Vitamin E inhibits inflammatory cell ROS release (respiratory burst) [48].

Antifibrotic Properties. Vitamin E inhibits TGF- $B 1$ production; D-alpha-tocopherol and $\alpha$-tocopherol succinate have been shown to inhibit cellular proliferation of fibroblasts in human pathological fibrosis $[49,50]$.

Anti-Inflammatory Properties. Vitamin E interferes with factor NF- $\kappa$ B, also hindering proinflammatory cytokine transcription; vitamin $\mathrm{E}$ has an anti-COX-2 mechanism; it inhibits cell proliferation through a protein kinase C (PKC) inhibition mechanism [51-53].

Furthermore, vitamin E inhibits platelet adhesion and aggregation, improves endothelial function, and can repair DNA $[54,55]$.

Literature Review. Vitamin E is the oldest substance still currently in use in PD treatment. Scardino and Scott (194849) and Steinberg (1951) pioneered the use of vitamin E in medical treatment of PD [56, 57]. In their 1948 study, after treating 23 patients with tocopherol, Scardino and Scott obtained a plaque size reduction in $91 \%$ of cases, curvature improvement in $78 \%$ of cases, and resolution of pain in all cases. Pryor and Farell (1983) and Safarinejad et al. (2007) observed no significant improvement after treating PD patients with tocopherol compared to placebo treatment $[58,59]$. However, several studies have shown that vitamin $\mathrm{E}$ is effective only when combined with other treatments (combination or multimodal therapy) [60-62]. In particular, our 2012 controlled study demonstrated the superiority of treatment results when adding vitamin $\mathrm{E}(600 \mathrm{mg} /$ daily $=$ group A) to a combination therapy (verapamil injection and iontophoresis + blueberries oral + propolis oral + topical Diclofenac/for 6 months = group B): (group A versus group B) success in reducing plaque size $97.14 \%$ versus $68.57 \%(p=$ 0.004 ); actual plaque size reduction $50.2 \%$ versus $35.8 \%$ ( $p=$ 0.027 ); penile curvature improvement $96.6 \%$ versus $48.4 \%$ $(p=0.0001)$; mean penile curvature decrease of $12.25^{\circ}$ versus $6.73^{\circ}(p=0.01)[62]$.

2.4.2. Carnitine. This molecule is very similar to an amino acid; in humans, it is synthesized in the liver, brain, and kidneys from essential amino acids lysine and methionine by ALC transferase. The carnitine system is comprised of L-carnitine, its esters (acetyl L-carnitine, propionyl-Lcarnitine), and a complex enzymatic system located in the mitochondrial membrane. It has been estimated that carnitine produced endogenously is $1.2 \mu \mathrm{mol}$ per day per $\mathrm{kg}$ of body weight, but in omnivorous human beings about $75 \%$ of carnitine in the body comes from diet, while $25 \%$ comes from de novo biosynthesis [63].

Meat is the main external source of carnitine, but it is present in lower concentrations in cod and dairy and in even lower concentrations in plant-based products. Its main role is that of mitochondrial long-chain fatty acid transport; therefore it works to convert fat to energy.

Antioxidant Properties. It is scavenger and neutralizer of superoxide anion, hydrogen peroxide, and peroxynitrite [64].

L-Carnitine inhibits proliferation and osteoblastic differentiation of fibroblasts [65].

Anti-Inflammatory Properties. L-Carnitine is able to reduce blood levels of C-reactive protein (CRP), interleukin-6 (IL-6), 
TABLE 2: Biological properties and mechanisms of action of antioxidants used in the treatment of Peyronie's disease.

\begin{tabular}{|c|c|c|}
\hline Active substance & $\begin{array}{l}\text { Biological } \\
\text { properties }\end{array}$ & Mechanisms of action \\
\hline \multirow{10}{*}{ Vitamin E } & \multirow{2}{*}{ Antioxidant } & (i) Scavenger activity against hydroxyl radical and lipid peroxyl radical \\
\hline & & (ii) Inhibition of respiratory/oxidative burst and relative release of ROS \\
\hline & \multirow{2}{*}{ Anti-inflammatory } & (i) Inhibition of NF-kappa-B activation and proinflammatory cytokine expression \\
\hline & & (ii) Inhibition of COX-2 activity \\
\hline & \multirow{3}{*}{ Antifibrotic } & (i) Inhibition of TGF-beta-1 \\
\hline & & (ii) Inhibition of fibroblast proliferation \\
\hline & & (iii) Inhibition of PDGF activity \\
\hline & \multirow{2}{*}{ Antiproliferative } & (i) Inhibition of protein kinase $\mathrm{C}$ activity \\
\hline & & (ii) DNA repair activity \\
\hline & Antiplatelet & (i) Antiadhesive and antiaggregating activity \\
\hline \multirow{8}{*}{ Carnitine } & \multirow{3}{*}{ Antioxidant } & (i) Scavenger activity against super oxide, hydrogen peroxide, and peroxynitrite \\
\hline & & (ii) Suppresses iNOS protein expression and nitric oxide radical production \\
\hline & & $\begin{array}{l}\text { (iii) Increase in eNOS expression (counteracting the negative effects of the nitric oxide } \\
\text { radical) }\end{array}$ \\
\hline & \multirow{3}{*}{ Anti-inflammatory } & (i) Downregulation of C-reactive protein, IL-6, and TNF- $\alpha$ expression \\
\hline & & (ii) Inhibition of NF-kappa-B activation and proinflammatory cytokine expression \\
\hline & & (iii) Upregulation of PPAR $\gamma$ \\
\hline & Antifibrotic & (i) Inhibition of fibroblast proliferation \\
\hline & Anticalcific & (i) Inhibition of osteogenic differentiation of fibroblasts \\
\hline \multirow{14}{*}{ Pentoxifylline } & \multirow{7}{*}{ Anti-inflammatory } & (i) Inhibition of respiratory/oxidative burst and relative release of ROS \\
\hline & & (ii) Hydroxyl radical scavenger \\
\hline & & (iii) Inhibition of lipid oxidation \\
\hline & & (iv) Downregulation of iNOS protein expression \\
\hline & & (i) Inhibition of NF-kappa-B activation and proinflammatory cytokine expression \\
\hline & & (ii) Inhibition of COX-2 expression \\
\hline & & (iii) Inhibition of TNF- $\alpha$ expression \\
\hline & \multirow{6}{*}{ Antifibrotic } & (i) Reduction of collagen deposition \\
\hline & & (ii) Inhibition of fibroblast proliferation \\
\hline & & (iii) Inhibition of myofibroblastic differentiation of fibroblasts \\
\hline & & (iv) Inhibition of TGF-beta-1 and PAI-1 expression \\
\hline & & (v) Stimulation of fibroblast apoptosis \\
\hline & & (vi) Nonspecific PDE inhibitory activity \\
\hline & Antiplatelet & (i) Antiaggregating activity \\
\hline \multirow{9}{*}{ Coenzyme Q10 } & \multirow{6}{*}{ Antioxidant } & $\begin{array}{l}\text { (i) Inhibition of increased production of ROS by blocking mitochondrial membrane } \\
\text { depolarization }\end{array}$ \\
\hline & & (ii) Scavenger activity against hydrogen peroxide and singlet oxygen \\
\hline & & (iii) Downregulation of iNOS protein expression \\
\hline & & (iv) Inhibition of excess of nitric oxide production \\
\hline & & (v) Inhibition of lipid peroxidation \\
\hline & & (vi) Regeneration activity of antioxidants vitamin $\mathrm{E}$ and vitamin $\mathrm{C}$ \\
\hline & \multirow{2}{*}{ Anti-inflammatory } & (i) Inhibition of NF-kappa-B expression \\
\hline & & (ii) Downregulation of IL-6, TNF- $\alpha$, MCP-1 protein, and IL-1-beta expression \\
\hline & Antifibrotic & (i) Inhibition of TGF-beta-1 \\
\hline
\end{tabular}


TABLe 2: Continued.

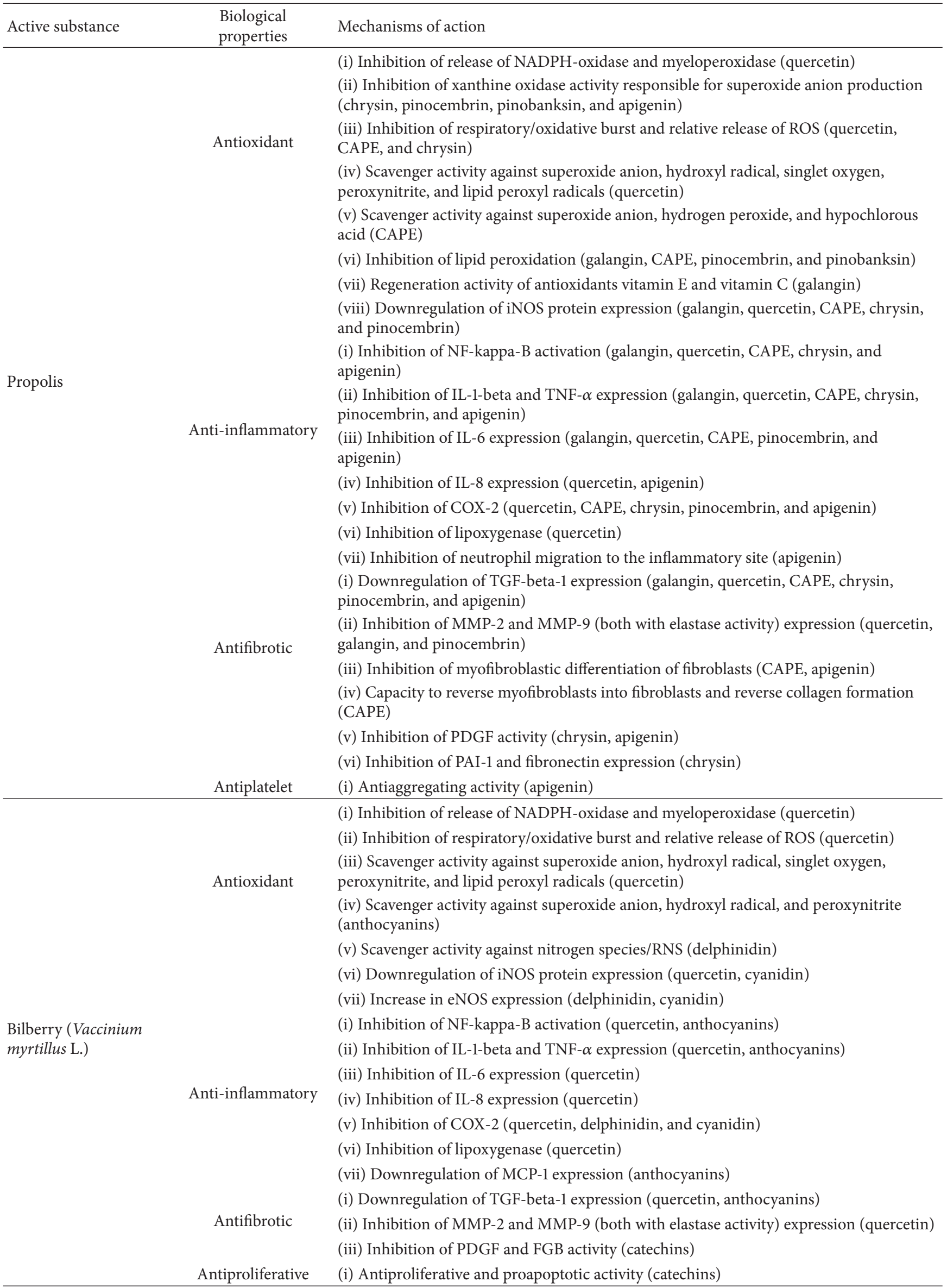


and TNF- $\alpha$ [66]. It can inhibit factor NF- $\kappa \mathrm{B}$, also suppressing nitric oxide radical production and iNOS protein expression [67]. The anti-inflammatory and antifibrotic properties of L-carnitine derive from its ability to cause upregulation of peroxisome proliferator-activated receptor- $\gamma(\operatorname{PPAR} \gamma)$ which can inhibit expression of proinflammatory cytokines (TGF$\beta 1$, TNF- $\alpha$, and IL-1) [68]. L-Carnitine also increases eNOS expression, contrasting the negative effects of nitric oxide radical and related reactive nitrogen species production (peroxynitrite, etc.) [69]. It is important to mention that L-carnitine is a peripheral antagonist of thyroid hormone action: Lcarnitine inhibits triiodothyronine (T3) and thyroxine (T4) entry into the cell nuclei. A randomized study proved that 2 and 4 grams/oral/daily of L-carnitine are capable of reversing hyperthyroidism symptoms [70]. Therefore, if at therapeutic doses ( $<2$ grams) there is no problem for euthyroid patients, hyperthyroid patients, or hypothyroid patients treated with thyroid hormones, caution should be exercised if patients to be treated with carnitine are hypothyroid. In case of longterm therapy with carnitine (at high doses) mild euphoria is possible as a side effect, as it negatively interferes with $\gamma$-aminobutyric acid (GABA), causing an antidepressantexcitatory effect.

Literature Review. Carnitine has been successfully used to treat PD. In their 2001 randomized controlled study, Biagiotti and Cavallini, after administering acetyl-L-carnitine (ALC) (1 $\mathrm{g}$ twice daily for 3 months) to patients with active-phase $\mathrm{PD}$, compared results with a control group (tamoxifen $20 \mathrm{mg}$ twice daily for 3 months): (ALC group versus tamoxifen controlled-group) erectile pain improvement $92 \%$ versus $50 \%$ of cases $(p<0.01)$; mean penile curvature decrease, $7.5^{\circ}$ versus $0.5^{\circ}(p<0.01)$; plaque size reduction $(\mathrm{mm} 2), 48.8$ versus $26.9 \mathrm{~mm}^{2}(p<0.01)$; inhibiting disease progression, $92 \%$ versus $46 \%$ [71].

In a subsequent controlled randomized study on patients with advanced resistant PD, Cavallini and Biagiotti (2002) administered propionyl-L-carnitine (PLC) (1 g twice daily) +10 intraplaque infiltrations (one/week) with verapamil $10 \mathrm{mg}$ for 3 months and compared results with those of the control group (tamoxifen $20 \mathrm{mg}$ twice/day +10 intraplaque infiltrations once weekly with verapamil $10 \mathrm{mg}$ for 3 months); they demonstrated that the PLC + verapamil association (versus tamoxifen + verapamil control group) was able to significantly reduce both plaque volume $(p<0.01)$ and penile curvature $(p<0.01)[72]$.

2.4.3. Pentoxifylline. PTX is a synthetic xanthine derivative structurally related to theophylline and caffeine. As hemorheologic agent, it was initially used to treat peripheral vascular diseases, cerebrovascular insufficiency, sickle cell disease, and diabetic neuropathy. PTX inhibits platelet aggregation and improves blood flow by increasing erythrocyte and leukocyte deformability [73].

Antioxidant Properties. They include inhibiting ROS release (respiratory burst) by neutrophils, inhibiting lipid oxidation, and interfering with oxygen-radical-mediated activation of proinflammatory transcription factor NF- $\kappa \mathrm{B}[74,75]$. Furthermore, PTX has been shown to have hydroxyl radical scavenging activity [76].

Anti-Inflammatory Properties. PTX reduces proinflammatory cytokines (TNF- $\alpha$, TGF- $\beta 1$, and IL-1), NF- $\kappa$ B, and COX-2 expression [77-79].

Antifibrotic Properties. Due mainly to its capacity to inhibit production of TGF- 31 , FGF, and PDGF [77-80], PTX can reduce collagen deposition, as well as having strong inhibitory effects on fibroblast proliferation, ECM synthesis, and myofibroblastic differentiation. Thanks to its capacity to inhibit TGF- $B 1$ and TNF- $\alpha$ production, PTX can also hinder production of PAI-1. PTX is also a nonspecific phosphodiesterase (PDE) inhibitor and therefore has further antifibrotic activity by reducing iNOS and collagen expression and stimulating fibroblast apoptosis within the tunica albuginea $[81,82]$.

Literature Review. Besides treatment of peripheral artery disease, PTX has been used multiple times in man to treat various inflammatory conditions associated with fibrosis (radiation-induced and pulmonary fibrosis, scleroderma, etc.). A 2003 article by Valente et al. described an experimental study which included PTX administration $(10 \mathrm{mg} / \mathrm{kg} /$ day/oral in drinking water for 45 days $)$ in rats with PD-like plaque elicited by injection of TGF- $\beta 1$ into the penile tunica albuginea [82]. PTX monotherapy resulted in an $80 \%-95 \%$ reduction in both plaque size and collagen/fibroblast ratio. The authors concluded that PTX was effective in stimulating fibroblast apoptosis in the tunica albuginea and therefore suggested PTX may be effective in reversing PD fibrosis [82]. The first article in which PTX was proposed as treatment for PD was published in 2006 [83]. It was a report about a 51-year-old Caucasian patient suffering from PD, treated with PTX, who suffered from moderate erectile dysfunction associated with two calcifications of the corpora cavernosa and 30-degree penile curvature; after treatment with PTX $400 \mathrm{mg} /$ three times daily for 6 months, curvature had decreased to about 10 degrees. The patient continued the same therapy for 2 more years; at follow-up the dorsal plaque had decreased in volume and consistency, erectile function had significantly improved, and ultrasound confirmed disappearance of dorsal calcification with persistence of ventral calcific plaque. In 2010, Lin et al. published in two articles appearing in the same journal, one shortly after the other, a study divided into two parts, concerning the effects of TGF- 31 and PTX on cultures of samples of tunica albuginea-derived fibroblasts (TADFs) from men with and without PD; in particular, it focused on the effects on collagen metabolism, elastin expression, and elastogenesis [77, 78]. The specimens of plaque containing tunica albuginea were harvested from 12 patients with chronic PD, during surgery for curvature correction. Biopsy samples of healthy tunica albuginea were taken from 6 patients during surgery for penile prosthesis positioning. The study yielded the following results: TGF- $\beta 1$ stimulates collagen and elastin production; treatment of 
TADF with PTX reduces the TGF- $\beta 1$-mediated increase in elastogenesis and collagen deposition. In 2011, the first cohort study was published in which PTX was used to treat a group of 62 patients with PD and sonographic evidence of penile calcification [84]. The study's control group did not receive PTX. Treatment consisted in PTX $400 \mathrm{mg} /$ three times daily (mean duration of treatment $=1.2$ years). After treatment, patients were reassessed with a clinical exam and gray-scale or duplex ultrasound. Compared to the no-treatment group, patients who took PTX had a reduction in calcification volume $(69.4 \%$ versus $33.3 \%, p=0.03)$. Moreover, PTX-treated patients were much more likely to have stabilization (no change) or improvement in their calcium burden compared to patients of the control group (91.9\% versus $44.4 \%, p<0.001$ ).

In 2012, a study assessed PTX efficacy in 74 PD patients using a combined therapy which included oral PTX $(400 \mathrm{mg} /$ three times daily) associated with oral L-arginine ( $1 \mathrm{~g} /$ twice daily) and verapamil injections (12 in total, every 2 weeks). Seventy-four PD patients were divided into two treatment groups: group I (39 patients), verapamil injections + oral therapy (L-arginine + PTX) + daily penile traction therapy (PTT) for 6 months; group II (35 patients), like group I but without PTT. Mean penile curvature improvement was $26.9^{\circ}$ in group I versus $20.9^{\circ}$ in group II. Although PTX was not used exclusively, the study demonstrated that combined treatment without PTT still led to significant penile curvature improvement [85]. In 2013, another report was published about a young PD patient who was treated successfully (significant plaque volume reduction) with a 2 year combined therapy (oral PTX/400 mg/3 times daily + oral tadalafil $/ 5 \mathrm{mg} / 3$ times a week + oral L-arginine $/ 2500 \mathrm{mg} /$ daily + oral PLC/250 mg/daily + oral vitamin B3/20 mg/daily + penile extender) [86]. Another report about exclusive use of PTX was published in 2014, describing PTX treatment in a 35-year-old PD patient with a large plaque in the distal third of the penis. Even though he had no bending, the patient complained of difficulty in coital penetration due to a lack of rigidity and tumescence in the terminal part of the penis. After oral PTX therapy ( $400 \mathrm{mg} / \mathrm{oral} / 3$ times daily) for 6 months, the patient had significant improvement of erectile function and glans tumescence, which made penetration possible [87]. In 2014, Alizadeh et al. published a study using PTX for treatment of PD. Ninety PD patients were randomized and divided into three treatment groups: group 1, oral PTX/1200 mg/day; group 2, verapamil injection/10 mg for up to 12 injections; group 3, oral PTX/1200 mg/day + intralesional verapamil injection. The outcomes were the following: (oral PTX versus intralesional verapamil versus oral PTX + intralesional verapamil) $\%$ of patients with plaque size reduction $=30$ versus 33 versus 33; $\%$ of patients with improvement in penile curvature $=26.7$ versus 36.7 versus $36.7 ; \%$ of patients with improvement in erectile dysfunction $=46.7$ versus 66.7 versus $86.7 ; \%$ of patients with pain reduction $=73.3$ versus 76.7 versus 80.0. Even in this study, PTX appeared effective in treating PD [88].

We published a controlled study last year in which PTX was used for 6 months in association with other antioxidant and anti-inflammatory substances for PD treatment [89]. All
307 patients of the study had PD in its evolutionary phase; the control group (group C, no treatment) included 101 patients.

The 206 treated patients were divided into two groups and differed only in whether they received penile PTX injections. Group A received PTX $100 \mathrm{mg} 12$ perilesional injections (twice a month for 6 months) + oral PTX $400 \mathrm{mg} /$ twice a day + oral propolis $600 \mathrm{mg} /$ daily + oral blueberry (Vaccinium myrtillus L., see below for a detailed description) $160 \mathrm{mg} /$ daily + oral vitamin E $600 \mathrm{mg} /$ daily + Diclofenac sodium 4\% gel twice daily, as topical treatment for 6 months; group $\mathrm{B}$ received the same therapy as group A, but without PTX injections. The most significant results were as follows: (group A versus group B) \% of patients with plaque size reduction $=100$ versus $79.7(p<0.001)$; actual mean plaque size reduction $=-46.9 \%$ versus $-24.8 \%(p<0.001)$; $\%$ of patients with improvement in penile curvature $=96.8$ versus 56.4 $(p<0.001)$; actual mean penile curvature reduction $=-10.1^{\circ}$ versus $-4.8^{\circ}(p<0.001)$; mean variation in $\%$ of penile curve angle $=-40.7$ versus $-21.7(p<0.001) ; \%$ of patients with complete disappearance of penile curvature $=6.3$ versus $1.2(p=0.128) ; \%$ of recovery of penile rigidity in patients with erectile dysfunction $=56.0$ versus $23.5(p=0.005) ; \%$ of patients with reduction in calcification size $=96.7$ versus $70.8(p=0.01)$; actual mean reduction in calcification size $=-54.0 \%$ versus $-40.2 \%(p<0.131) ; \%$ of patients with complete disappearance of penile calcification $=9.6$ versus $8.33(p=0.863)$. Incidence of side-effects after oral administration of PTX: blood pressure drop $0.46 \%$, tachycardia $1.38 \%$, dizziness $0.92 \%$, skin rash $1.85 \%$, headache $0.97 \%$, hot flashes $0.97 \%$, vomiting $0.48 \%$, dyspepsia $2.42 \%$, nausea $2.91 \%$, meteorism $3.88 \%$, and cumulative gastrointestinal adverse effects $9.69 \%$. The only adverse effect of the penile PTX injection was local bruising at the infiltration site $(3.57 \%$ incidence) [89]. The most important outcome was that PTX via perilesional penile injection was shown to be effective in treating PD and greatly statistically significantly improved the (already positive) results obtained with combined oral therapy alone. This study confirmed a peculiarity of PTX already mentioned in previous studies: a capacity to cause almost complete clearance of penile calcifications $[83,84]$.

2.4.4. Coenzyme Q10 (CoQ10). CoQ10, also known as ubiquinone, ubidecarenone, coenzyme $\mathrm{Q}, \mathrm{CoQ}$, or Q10, is a fat-soluble molecule involved in mitochondrial electron transport and oxidative phosphorylation and necessary for cellular respiration and adenosine triphosphate (ATP) production. The molecule exists in both reduced (ubiquinol, CoQ10H2) and oxidized (ubiquinone, CoQ10) form. CoQ10 inhibits increased ROS production, by blocking mitochondrial membrane depolarization. In its reduced form, CoQ10 acts as a potent endogenous antioxidant, interacting with oxygen-related radicals, hydrogen peroxide, and singlet oxygen and inhibiting lipid peroxidation (Table 1) [90]. CoQ10 prevents nitrosative stress by inhibition of excess nitric oxide radical production, and it participates in vitamin $\mathrm{E}$ and $\mathrm{C}$ regeneration [91, 92]. CoQ10 has a strong anti-inflammatory and antifibrotic activity, producing a decrease of proinflammatory cytokines TNF- $\alpha$, IL-6, TGF- $\beta 1$, and monocyte chemoattractant protein-1 (MCP-1), one of the cytokines 
that regulate migration and infiltration of monocytesmacrophages; furthermore, higher MCP-1 expression was found in PD-fibroblasts [93]. In addition, CoQ10 decreases gene expression of IL- $1 \beta, \mathrm{NF}-\kappa \mathrm{B}$, and iNOS [94].

Literature Review. A single study exists where CoQ10 was used to treat $\mathrm{PD}$; this prospective, double-blind placebocontrolled randomized clinical trial demonstrated significant positive results: 186 patients affected by early chronic PD were divided into two groups of 93 patients each (treatment group and no-medication control group) [95]. Patients in the treatment group were treated with CoQ10, $300 \mathrm{mg} /$ daily for 24 weeks. At the end of treatment, results were the following: (CoQ10 group versus placebo group) change in plaque size $=$ $-40.0 \%$ versus $+35.7 \%$; $\%$ of patients with objective curvature improvement $=54.3$ versus $12.2 ; \%$ of patients with increased curvature $=14.8$ versus 69.5 ; $\%$ of patients with improvement of sexual function $=51.9$ versus 8.6 [95].

2.4.5. Propolis. Propolis has been used by mankind since ancient times for its curative properties. It is plant-based and consists in a mixture of compounds which bees (Apis mellifera L.) extract from tree bark and buds. The resinous substances extracted by the bees are then processed with the addition of wax, pollen, and saliva enzymes. The final product is a resinous mixture with a color varying in shade from yellow to black. Bees produce propolis to seal any small opening in their beehives, protecting themselves from the cold, rain, wind, and possible attacks by other insects. The most interesting property of propolis is that of preventing disease, protecting the bees in the beehive from parasites, bacteria, viruses, and microbes in general. Many polyphenolic compounds, flavonoids, phenolic acids (caffeic acid and cinnamic acid), and esters and fatty acids have been found in propolis. Flavonoids commonly contained in propolis are acacetin, apigenin, catechin, chrysin, galangin, kaempferol, luteolin, myricetin, naringenin, pinocembrin, quercetin, and rutin. Propolis also contains resveratrol (a natural stilbene derivative) and several minerals ( $\mathrm{Mg}, \mathrm{Ca}, \mathrm{I}$, $\mathrm{K}, \mathrm{Na}, \mathrm{Cu}, \mathrm{Zn}, \mathrm{Mn}$, and F), as well as vitamins (B1, B2, B6, C, and E) [96]. Since propolis indirectly derives from plants, its composite content varies depending on the geographical position and climate of the area of production. For instance, the characteristic compounds of Chinese propolis are caffeic acid, caffeic acid phenethyl ester (CAPE), caffeic acid benzyl ester, 5-methoxy pinobanksin, pinobanksin, pinobanksin-3O-acetate, pinocembrin, chrysin, and galangin [97]. Brazilian propolis contains the following: liquiritigenin, daidzein, dalbergin, isoliquiritigenin, formononetin, biochanin A, galangin, kaempferol, pinostrobin, and pinocembrin [98]. Geographical differences of propolis are significant. CAPE is present in amounts greater than $10 \mathrm{mg} / \mathrm{g}$ in propolis extracts from Australia, China (up to $29 \mathrm{mg} / \mathrm{g}$ ), Hungary, New Zealand, Uruguay, and Uzbekistan. Less than $10 \mathrm{mg} / \mathrm{g}$ of CAPE is found instead in propolis extracts from Argentina, Bulgaria, Chile, Ukraine, and USA [99]. CAPE is scarcely present or even absent in propolis extracts from Brazil, South Africa, and Thailand. Poplars, and their buds in particular, are considered the main indirect source of propolis in Europe and North America, nontropical Asia, New Zealand, and North Africa (especially the Nile delta) [100]. Considering the heterogeneous nature of the composition of propolis, pharmaceutical industries use standard quantities of the individual compounds by chemical extraction, choosing the substances based on their particular properties.

\section{(i) Properties of the Most Common Substances Contained in Propolis}

\section{Galangin}

Antioxidative Properties. It affects lipid peroxidation and helps preserve other antioxidants such as vitamin $\mathrm{E}$ and vitamin C $[101,102]$.

Antifibrotic Properties. It diminishes gene expression of TGFß1, MMP-2, and MMP-9 [103].

Anti-Inflammatory Properties. It inhibits factor NF- $\kappa \mathrm{B}$ and reduces production of IL-1 $\beta$, TNF- $\alpha$, IL-6, and iNOS [104].

\section{Quercetin}

Antioxidant Properties. Quercetin decreases neutrophil activity (respiratory burst and degranulation) and inhibits release of NADPH-oxidase and MPO by decreasing generation of superoxide and derived ROS [105]. It is able to scavenge highly reactive species such as peroxynitrite, hydroxyl radical, superoxide anion, singlet oxygen, and lipid peroxyl radicals [106].

Anti-Inflammatory Properties. It inhibits production of TNF$\alpha$, IL-8, IL- $1 \alpha$, IL- $1 \beta$, and IL- 6 through inhibition of NF- $\kappa \mathrm{B}$ activation [107]. Moreover quercetin inhibits inflammatory enzymes cyclooxygenase (COX), lipoxygenase (LOX), and iNOS [108].

Antifibrotic Properties. It suppresses TGF- $\beta$-induced collagen production and inhibits matrix metalloproteinases (MMP-2 and MMP-9), which are normally inhibited by PAI-1 [109].

Caffeic Acid Phenethyl Ester (CAPE). CAPE exhibits a stronger antioxidant activity than galangin [102]. It hinders oxidative burst and related polymorphonuclear neutrophil production of superoxide anion, hydrogen peroxide, and hypochlorous acid (HOCl) by activated leukocytes; moreover, it suppresses lipid peroxidation activity [110].

Anti-Inflammatory Properties. CAPE is a potent, specific inhibitor of NF- $\kappa \mathrm{B}$-dependent transcriptional activity, as well as cyclooxygenase (COX-1 and COX-2) and lipoxygenase activity [110-112]. Moreover, CAPE inhibits iNOS, TNF- $\alpha$, IL-1 $\beta$, and IL-6 production $[110,111]$.

Antifibrotic Properties. CAPE attenuates TGF- $\beta$-mediated collagen synthesis, inhibits peroxynitrite-augmented TGF$\beta 1$ release, counteracts TGF- $\beta$-induced differentiation of fibroblasts into myofibroblasts, and the concurrent formation of collagen; it is capable of partially reversing myofibroblasts into fibroblasts and reversing collagen formation [112, 113]. 


\section{Chrysin}

Antioxidant Properties. It inhibits xanthine oxidase activity, which is responsible for superoxide anion production; it also inhibits the release of NADPH-oxidase and the oxidative burst of neutrophils [105].

Anti-Inflammatory Properties. It inhibits NF- $\kappa \mathrm{B}$ and iNOS enzyme activity and cyclooxygenase- (COX-) 2 and IL- $1 \beta$ gene expression, significantly inhibiting the release of $\mathrm{NO}$, TNF- $\alpha$, and related increase in PAI-1 $[114,115]$.

Antifibrotic Properties. It suppresses TGF- $\beta$ and fibronectin expression; it also inhibits the profibrotic activity of PDGF $[116,117]$.

Pinocembrin. Pinocembrin possesses a high oxygen radical antioxidant capacity and nitrite scavenging capacity, inhibiting xanthine oxidase activity, which usually induces the generation of superoxide radicals; it also inhibits lipid peroxidation $[118,119]$.

Anti-Inflammatory Properties. It inhibits production of TNF$\alpha$, IL- $1 \beta$, and IL-6, as well as iNOS and COX-2 expression [120].

Antifibrotic Properties. It inhibits TGF- $\beta$ and MMP-2 and MMP-9 expression [121].

\section{Pinobanksin}

Antioxidant Capacity. It inhibits xanthine oxidase activity, which is responsible for superoxide radical production; it can also inhibit lipid peroxidation [118, 119]. Pinobanksin also has antiproliferative and proapoptotic activity [122].

Apigenin. Apigenin is an antioxidant; it inhibits xanthine oxidase activity responsible for ROS and hydrogen peroxide production.

Anti-Inflammatory Activity. It prevents migration of neutrophils toward the inflammatory site; it inhibits platelet aggregation, hindering the cyclooxygenase (COX) pathway; it also inhibits production of proinflammatory cytokines (IL-1 $\beta$, TNF- $\alpha$, IL- 6 , and IL- 8 ) through inhibition of the activation of factor NF- $\kappa$ B [123-125].

Antifibrotic Properties. It inhibits the expression of TGF- $\beta 1$ and PDGF, therefore blocking collagen production; apigenin also inhibits differentiation of fibroblasts into myofibroblasts [125].

Literature Review. Cuban urologists (Lemourt et al., 1998) were the first authors to publish a study on the use of propolis in the treatment of PD, as they discovered by serendipity that propolis could cure the disease: they had noticed that a patient suffering from PD who had been treated with propoleum (oil of propolis) due to giardiasis had reported a "spontaneous" improvement in his penile curvature; they therefore began to administer propolis to several PD patients, subsequently publishing various studies reporting excellent clinical results [126-129]. In one of their studies, they analyzed the effects of propolis on $34 \mathrm{PD}$ patients, assessing after 6 months two different daily doses of propolis (300 and $900 \mathrm{mg}$ ) in two respective groups (each made up of 17 patients) and concluded that patients treated with $900 \mathrm{mg} /$ daily had superior clinical results; furthermore, clinical improvement and plaque volume reduction occurred earlier in this group [128]. In another study, the same authors studied the effects of propolis on PD in three treatment groups: (group 1) propoleum $900 \mathrm{mg} /$ daily for over six months (10 patients); (group 2) 10 laser sessions every 2 months for over six months (8 patients); (group 3) propoleum $900 \mathrm{mg} /$ daily + 10 laser sessions every 2 months (10 patients). The best outcomes in terms of curvature reduction were obtained in the group of patients treated only with propolis (mean penile curvature improvement: $-10.8^{\circ}$ ); in the patients of the propolis + laser group, the curvature improvement was slightly inferior $\left(-10.3^{\circ}\right)$; only a few patients in the laser group referred to improvement $\left(-8.0^{\circ}\right)$ while a progression in curvature was observed in the remaining patients in this group, with a mean increase of $12.6^{\circ}$; as to plaque volume, mean US-measured reduction was $2.3 \mathrm{~mm}$ (only propolis group) and $12.16 \mathrm{~mm}$ (propolis + laser group); the laser group ultrasound results were not comparable due to the low number of patients compared to the other groups [129]. Another study where propolis was used to treat PD was published by Favilla et al. (2014); the authors used propolis in combination with other antioxidants and verapamil in patients with initial-phase $\mathrm{PD}$, assessing in particular the efficacy of associating intralesional verapamil injection (10 mg weekly for 12 weeks) and oral antioxidants (group B) compared with verapamil injection monotherapy (group A). The oral antioxidant therapy consisted in a tablet/daily (for 3 months) with the following composition formula: propolis $100 \mathrm{mg}$, blueberry anthocyanins $80 \mathrm{mg}$, para-aminobenzoic acid $100 \mathrm{mg}$, Muira Puama $25 \mathrm{mg}$, soya isoflavones $50 \mathrm{mg}$, Persea americana $50 \mathrm{mg}$, vitamin E $36 \mathrm{mg}$, and Damiana $25 \mathrm{mg}$ [61]. Although no significant differences were observed between the two groups in mean plaque size change (group A versus group $\mathrm{B}=-0.38 \mathrm{~cm} 3$ versus $-0.29 \mathrm{~cm} 3)$ and mean penile curvature improvement $\left(-10.86^{\circ}\right.$ versus $\left.-11.97^{\circ}\right)$, statistically significant results were obtained in group B in regard to orgasmic function (subdomain of 15-question International Index of Erectile Function, IIEF), intercourse satisfaction (subdomain of IIEF), overall satisfaction (subdomain of IIEF), and pain/visual analogue score (VAS) [61]. We ourselves have published five controlled studies in which we used propolis associated with other substances, always with excellent, statistically significant results; the most recent one of these studies is discussed in detail above in the section on pentoxifylline, and the others are in the following paragraph on bilberry [62, 89, 130-132].

2.4.6. Bilberry (Vaccinium myrtillus L.). Bilberry is also known as "European wild blueberry" and "Whortleberry." Bilberry grows in forest undergrowth, generally in mountainous areas in North America and Northern and Central Europe. It contains numerous flavonoids, including anthocyanins, pigments that give fruit its color. Anthocyanins 
contained in bilberry are cyanidin, delphinidin, petunidin, malvidin, and peonidin; cyanidin is present in higher concentrations compared to the other anthocyanins (mean amount $0.053 \mu \mathrm{g} / \mathrm{mL}$ ); delphinidin and petunidin are present 2.5 times less, while malvidin and peonidin are present in very low concentrations (mean amount $0.011-0.012 \mu \mathrm{g} / \mathrm{mL}$ ) [133]. Although anthocyanins are the most preponderant substances in bilberry, it contains a variety of phenolic compounds, including quercetin, tannins, ellagitannins, and flavonols such as catechin, epicatechin, gallocatechin, and epigallocatechin (the latter two only in unripe fruit), and small quantities of vitamin C $[134,135]$. Since it contains quercetin (already mentioned above when discussing propolis) bilberry has antioxidant, anti-inflammatory, and antifibrotic properties [105-109]. Due to its high anthocyanin content, bilberry has powerful antioxidant effects against superoxide anion, hydroxyl radical, and peroxynitrite [136]. Anthocyanins, especially delphinidin, quickly reacts with extended oxidation products of nitric oxide radical (RNS) [137]. Anthocyanins also reduce the levels of NF- $\kappa \mathrm{B}$, TNF$\alpha$, and MCP-1, which regulates migration and infiltration of monocytes-macrophages [138]. Furthermore, delphinidin and cyanidin inhibit COX-2 and increase the protein level of eNOS; cyanidin is also able to cause downregulation of iNOS [139-141]. Anthocyanins can also inhibit phosphodiesterase (PDE) [142]. Bilberries (thanks to their high content of anthocyanins) also have antifibrotic action, suppressing TGF$\beta$-induced collagen production [109]. Catechins contained in bilberries inhibit PDGF and FGF; moreover catechins show antiproliferative and proapoptotic activity [143].

Literature Review. In six controlled studies bilberry was used in combined PD therapy (see PTX and propolis sections above). Statistically significant results after treatment were found in all these studies [61, 62, 89, 130-132]. In particular, in our 2013 study, European blueberry was administered to 41 patients (group A) for 18 months, $160 \mathrm{mg} /$ daily + verapamil $10 \mathrm{mg}$ penile perilesional injections (twice monthly for 6 months and then once monthly for 12 months, for a total of 24 injections) + iontophoresis with verapamil $5 \mathrm{mg}$ daily + propolis $600 \mathrm{mg} /$ daily + vitamin E $600 \mathrm{mg} /$ daily + topical Diclofenac $4 \% /$ daily. The control group (group B) was made up of 41 patients who received no treatment [132]. After 18 months of treatment, plaque size reduction occurred in $100.0 \%$ of patients in group A and none in group B $(p<$ 0.0001 ); on the contrary, in group B plaque size always increased; in group $\mathrm{A}$, mean plaque size reduction was $-73.6 \%$, while in group $B$, there was a mean increase in plaque size $=+118.7 \%(p=0.000)$; in group A, penile curvature improvement occurred in $81.5 \%$ of cases versus only $8.1 \%$ in group $\mathrm{B}$; in group $\mathrm{A}$, mean decrease of penile curvature angle was $-16.74^{\circ}$ while in group B it was $-4.0^{\circ}(p=0.019)$ [132]. In the no-treatment group, penile curvature improved in only a few cases $(8.1 \%=3 / 41$ cases $)$; actually, in these cases the disease had progressed with an increase in plaque size which resulted in changes of the architectural structure of the penis that led to a paradoxical improvement in curvature.

\section{Discussion and Conclusions}

As can be gathered from the number of references in our article, numerous studies have demonstrated the fundamental role played by oxidative stress in PD pathogenesis, and several studies have described successful use of various antioxidants in PD treatment. Oxidative stress is an integral part of the disease, influencing its progression; in the very early stages of PD, the inflammatory infiltrate cells begin to produce high quantities of ROS and proinflammatory and profibrotic cytokines, with consequent activation of transcription factor NF- $\kappa \mathrm{B}$ which induces iNOS production and subsequent release of high nitric oxide radical concentrations. The next chemical reaction cascade leads to production of high amounts of reactive nitrogen species, particularly peroxynitrite, which can damage cells and tissue by lipid peroxidation and DNA fragmentation. As described above, inflammatory cytokine- and NF- $\kappa \mathrm{B}$-induced expression of iNOS leads to overproduction of nitric oxide radical, which reacting with superoxide anion causes peroxynitrite production [34]. Oxidative stress, furthermore, is an important factor in the possible onset of erectile dysfunction in PD, as hyperproduction of superoxide anion and peroxynitrite reduces nitric oxide concentration available for cavernosal muscle relaxation, resulting in long-term endothelial damage; superoxide anion is also reported to have a direct vasoconstriction effect $[44,144]$. The presence of high iNOS concentrations has been proven in the cavernous tissue of men with PD [34]. The exact role of iNOS was long unclear, and a number of authors attributed a protective, antifibrotic role to it $[39,145]$. Other authors, instead, proved that iNOS inhibition and peroxynitrite scavenging suppressed evolution of the inflammatory response and the normal course of collagen-induced diseases [146, 147]. Moreover, numerous studies listed in our literature review proved that iNOS inhibition after treatment with antioxidants (in PD patients) can have antifibrotic effects, resulting in significant clinical improvement [60-62, 71, 72, 82-89, 95, 128-132].

Since ROS damage occurs during the early stages of the disease, the treatment with antioxidants is only indicated in the initial stages of PD and not in the stabilization phase. For the same reason, the antioxidant therapy should be started immediately at the earliest diagnosis of the disease. Therefore, a "watchful waiting behavior" is not justified at the first time of PD diagnosis.

While conservative therapies commonly used in the early stages of PD include oral substances (Potaba, tamoxifen, colchicine, and vitamin E), intralesional treatment (verapamil, interferon, steroids, and more recently collagenase clostridium histolyticum-Xiaflex), and local physical treatment (iontophoresis, extracorporeal shock wave therapyESWT, and penile extender), the significant results obtained by emerging treatments with the antioxidants cited in this article suggest these therapeutic agents (which are also antifibrotic and anti-inflammatory) interfere at several levels with the disease's pathogenetic mechanisms (Table 2); combination therapy is therefore an effective treatment strategy today, capable of curing early-stage $\mathrm{PD}$, yielding better results than those traditionally obtained with a single substance. 
Combination therapy outcomes are interesting for good clinical practice and also confirm the fundamental role played by oxidative stress in PD. However, further prospective randomized placebo-controlled studies are needed to evaluate the efficacy of emerging antioxidant therapies.

\section{Conflicts of Interest}

The authors declare that there are no conflicts of interest regarding the publication of this paper.

\section{References}

[1] U. Schwarzer, F. Sommer, T. Klotz, M. Braun, B. Reifenrath, and U. Engelmann, "The prevalence of Peyronie's disease: results of a large survey," BJU International, vol. 88, no. 7, pp. 727-730, 2001.

[2] D. B. DiBenedetti, D. Nguyen, L. Zografos, R. Ziemiecki, and X. Zhou, "A Population-based study of peyronie's disease: prevalence and treatment patterns in the United States," Advances in Urology, vol. 2011, Article ID 282503, 9 pages, 2011.

[3] A. P. Saboeiro, J. J. Pokorny, S. I. Shehadi, K. S. Virgo, and F. E. Johnson, "Racial distribution of dupuytren's disease in department of veterans affairs patients," Plastic \& Reconstructive Surgery, vol. 106, no. 1, pp. 71-75, 2000.

[4] J. P. Jarow and F. C. Lowe, "Penile trauma: an etiologic factor in Peyronie's disease and erectile dysfunction," The Journal of Urology, vol. 158, no. 4, pp. 1388-1390, 1997.

[5] C. J. Devine Jr., K. D. Somers, G. H. Jordan, and S. M. Schlossberg, "Proposal: trauma as the cause of the Peyronie's lesion," Journal of Urology, vol. 157, no. 1, pp. 285-290, 1997.

[6] A. I. El-Sakka, E. Salabas, M. Dinçer, and A. Kadioglu, "The pathophysiology of Peyronie's disease," Arab Journal of Urology, vol. 11, no. 3, pp. 272-277, 2013.

[7] R. Rompel, G. Mueller-Eckhardt, I. Schroeder-Printzen, and W. Weidner, "HLA antigens in Peyronie's disease," Urologia Internationalis, vol. 52, no. 1, pp. 34-37, 1994.

[8] A. S. Herati and A. W. Pastuszak, "The Genetic Basis of Peyronie Disease: A Review," Sexual Medicine Reviews, vol. 4, no. 1, pp. 85-94, 2016.

[9] G. H. Dolmans, P. M. Werker, I. J. de Jong, R. J. Nijman, C. Wijmenga, and R. A. Ophoff, "WNT2 Locus Is Involved in Genetic Susceptibility of Peyronie's Disease," Journal of Sexual Medicine, vol. 9, no. 5, pp. 1430-1434, 2012.

[10] J. Byström and C. Rubio, "Induratio penis plastica (peyronie's disease): Clinical features and etiology," Scandinavian Journal of Urology and Nephrology, vol. 10, no. 1, pp. 12-20, 1976.

[11] K. D. Somers, E. N. Sismour, G. L. Wright Jr., C. J. Devine Jr., D. A. Gilbert, and C. E. Horton, "Isolation and characterization of collagen in Peyronie's disease," Journal of Urology, vol. 141, no. 3 I, pp. 629-631, 1989.

[12] J. P. Pryor and D. J. Ralph, "Clinical presentations of Peyronie's disease," International Journal of Impotence Research, vol. 14, no. 5, pp. 414-417, 2002.

[13] C. J. Nelson, C. Diblasio, M. Kendirci, W. Hellstrom, P. Guhring, and J. P. Mulhall, "The chronology of depression and distress in men with peyronie's disease," Journal of Sexual Medicine, vol. 5, no. 8, pp. 1985-1990, 2008.

[14] W. Weidner, I. Schroeder-Printzen, W.-H. Weiske, and R. Vosshenrich, "Sexual dysfunction in Peyronie's disease: An analysis of 222 patients without previous local plaque therapy," Journal of Urology, vol. 157, no. 1, pp. 325-328, 1997.
[15] E. Akkus, S. Carrier, K. Baba et al., "Structural alterations in the tunica albuginea of the penis: Impact of Peyronie's disease, ageing and impotence," British Journal of Urology, vol. 79, no. 1, pp. 47-53, 1997.

[16] LA. Levine and S. Larsen, "Diagnosis and management of peyronie disease," in Campbell-Walsh Urology, A. J. Wein, L. R. Kavoussi, A. W. Partin, and C. A. Peters, Eds., vol. 1, Chap 31, pp. 722-748, Elsevier Saunders, Philadelphia, Pa, USA, 11th edition, 2015.

[17] G. Garaffa, L. W. Trost, E. C. Serefoglu, D. Ralph, and W. J. G. Hellstrom, "Understanding the course of Peyronie's disease," International Journal of Clinical Practice, vol. 67, no. 8, pp. 781788, 2013.

[18] G. Brock, G.-L. Hsu, L. Nunes, B. von Heyden, and T. F. Lue, "The anatomy of the tunica albuginea in the normal penis and Peyronie's disease," Journal of Urology, vol. 157, no. 1, pp. 276281, 1997.

[19] G.-. Hsu, G. Brock, B. Von Heyden, L. Nunes, T. F. Lue, and E. A. Tanagho, "The distribution of elastic fibrous elements within the human penis," British Journal of Urology, vol. 73, no. 5, pp. 566-571, 1994.

[20] K. D. Somers and D. M. Dawson, "Fibrin deposition in Peyronie's disease plaque," Journal of Urology, vol. 157, no. 1, pp. 311315, 1997.

[21] V. Gentile, A. Modesti, G. La Pera et al., "Ultrastructural and immunohistochemical characterization of the tunica albuginea in Peyronie's disease and veno-occlusive dysfunction," Journal of Andrology, vol. 17, no. 2, pp. 96-103, 1996.

[22] N. F. Gonzalez-Cadavid, T. R. Magee, M. Ferrini, A. Qian, D. Vernet, and J. Rajfer, "Gene expression in Peyronie's disease," International Journal of Impotence Research, vol. 14, no. 5, pp. 361-374, 2002.

[23] S. K. Agarwal, "Integrins and cadherins as therapeutic targets in fibrosis," Frontiers in Pharmacology, vol. 5, article 131, 2014.

[24] S. M. Wahl, G. L. Costa, D. E. Mizel, J. B. Allen, U. Skaleric, and D. F. Mangan, "Role of transforming growth factor beta in the pathophysiology of chronic inflammation.," Journal of Periodontology, vol. 64, no. 5, pp. 450-455, 1993.

[25] J.-K. Ryu, W.-J. Kim, M.-J. Choi et al., "Inhibition of histone deacetylase 2 mitigates profibrotic TGF- $\beta 1$ responses in fibroblasts derived from Peyronie's plaque," Asian Journal of Andrology, vol. 15, no. 5, pp. 640-645, 2013.

[26] R. B. Moreland and A. Nehra, "Pathophysiology of Peyronie's disease," International Journal of Impotence Research, vol. 14, no. 5, pp. 406-410, 2002.

[27] M. Del Carlo, A. A. Cole, and L. A. Levine, "Differential Calcium Independent Regulation of Matrix Metalloproteinases and Tissue Inhibitors of Matrix Metalloproteinases by Interleukin$1 \beta$ and Transforming Growth Factor- $\beta$ in Peyronie's Plaque Fibroblasts," Journal of Urology, vol. 179, no. 6, pp. 2447-2455, 2008.

[28] D. R. Edwards, K. J. Leco, P. P. Beaudry, P. W. Atadja, C. Veillette, and K. T. Riabowol, "Differential effects of transforming growth factor- $\beta 1$ on the expression of matrix metalloproteinases and tissue inhibitors of metalloproteinases in young and old human fibroblasts," Experimental Gerontology, vol. 31, no. 1-2, pp. 207223, 1996.

[29] JP. Mulhall, "The clinical implications of basic science research in Peyronies disease, a guide to clinical management," in Current clinical urology: Peyronie's disease, LA. Levine, Ed., pp. 39-58, Humana Press, Totowa, NJ, USA, 2007. 
[30] S. C. Sikka and W. J. G. Hellstrom, "Role of oxidative stress and antioxidants in Peyronie's disease," International Journal of Impotence Research, vol. 14, no. 5, pp. 353-360, 2002.

[31] H. Sakurai, N. Shigemori, K. Hasegawa, and T. Sugita, "TGF$\beta$-activated kinase 1 stimulates NF- $\kappa \mathrm{B}$ activation by an NF$\kappa \mathrm{B}$-inducing kinase-independent mechanism," Biochemical and Biophysical Research Communications, vol. 243, no. 2, pp. 545549, 1998.

[32] D. Vernet, G. Nolazco, L. Cantini et al., "Evidence that osteogenic progenitor cells in the human tunica albuginea may originate from stem cells: implications for peyronie disease," Biology of Reproduction, vol. 73, no. 6, pp. 1199-1210, 2005.

[33] E. Lambert, E. Dassé, B. Haye, and E. Petitfrère, "TIMPs as multifacial proteins," Critical Reviews in Oncology/Hematology, vol. 49, no. 3, pp. 187-198, 2004.

[34] T. J. Bivalacqual, H. C. Champion, and W. J. G. Hellstrom, "Implications of nitric oxide synthase isoforms in the pathophysiology of Peyronie's disease," International Journal of Impotence Research, vol. 14, no. 5, pp. 345-352, 2002.

[35] G. Paulis and T. Brancato, "Inflammatory mechanisms and oxidative stress in Peyronie's disease: Therapeutic "rationale" and related emerging treatment strategies," Inflammation and Allergy - Drug Targets, vol. 11, no. 1, pp. 48-57, 2012.

[36] M. Huleihel, A. Douvdevani, S. Segal, and R. N. Apte, "Regulation of interleukin 1 generation in immune-activated fibroblasts," European Journal of Immunology, vol. 20, no. 4, pp. 731738, 1990.

[37] K. Sasaki, T. Hattori, T. Fujisawa, K. Takahashi, H. Inoue, and M. Takigawa, "Nitric oxide mediates interleukin-1-induced gene expression of matrix metalloproteinases and basic fibroblast growth factor in cultured rabbit articular chondrocytes," Journal of Biochemistry, vol. 123, no. 3, pp. 431-439, 1998.

[38] R. J. Van't Hof, K. J. Armour, L. M. Smith et al., "Requirement of the inducible nitric oxide synthase pathway for IL1- induced osteoclastic bone resorption," Proceedings of the National Academy of Sciences of the United States of America, vol. 97, no. 14, pp. 7993-7998, 2000.

[39] H. H. Davila, T. R. Magee, D. Vernet, J. Rajfer, and N. F. Gonzalez-Cadavid, "Gene transfer of inducible nitric oxide synthase complementary DNA regresses the fibrotic plaque in an animal model of Peyronie's disease," Biology of Reproduction, vol. 71, no. 5, pp. 1568-1577, 2004.

[40] H. H. Davila, T. R. Magee, F. I. Zuniga, J. Rajfer, and N. F. Gonzalez-Cadavid, "Peyronie's disease associated with increase in plasminogen activator inhibitor in fibrotic plaque," Urology, vol. 65 , no. 4, pp. 645-648, 2005.

[41] M. Sasaki, M. Kashima, T. Ito et al., "Differential regulation of metalloproteinase production, proliferation and chemotaxis of human lung fibroblasts by PDGF, interleukin- $1 \beta$ and TNF- $\alpha$," Mediators of Inflammation, vol. 9, no. 3-4, pp. 155-160, 2000.

[42] M. M. Chaturvedi, M. Higuchi, and B. B. Aggarwal, "Effect of tumor necrosis factors, interferons, interleukins, and growth factors on the activation of NF- $\kappa \mathrm{B}$ : Evidence for lack of correlation with cell proliferation," Lymphokine and Cytokine Research, vol. 13, no. 5, pp. 309-313, 1994.

[43] R.-M. Liu, "Oxidative stress, plasminogen activator inhibitor 1, and lung fibrosis," Antioxidants and Redox Signaling, vol. 10, no. 2, pp. 303-319, 2008.

[44] A. Agarwal, K. C. Nandipati, R. K. Sharma, C. D. Zippe, and R. Raina, "Role of oxidative stress in the pathophysiological mechanism of erectile dysfunction," Journal of Andrology, vol. 27, no. 3, pp. 335-347, 2006.
[45] E. Nava and S. Llorens, "The paracrine control of vascular motion. A historical perspective," Pharmacological Research, vol. 113, pp. 125-145, 2016.

[46] R. M. J. Palmer, D. S. Ashton, and S. Moncada, "Vascular endothelial cells synthesize nitric oxide from L-arginine," Nature, vol. 333, no. 6174, pp. 664-666, 1988.

[47] W. W. Scott and P. L. Scardino, "A new concept in the treatment of peyronie's disease," Southern Medical Journal, vol. 41, no. 2, pp. 173-177, 1948.

[48] O. Cachia, J. El Benna, E. Pedruzzi, B. Descomps, M.-A. Gougerot-Pocidalo, and C.-L. Leger, " $\alpha$-Tocopherol inhibits the respiratory burst in human monocytes: Attenuation of p47(phox) membrane translocation and phosphorylation," Journal of Biological Chemistry, vol. 273, no. 49, pp. 3280132805, 1998.

[49] A. Tasanarong, S. Kongkham, S. Duangchana, S. Thitiarchakul, and S. Eiam-Ong, "Vitamin E ameliorates renal fibrosis by inhibition of TGF-beta/Smad2/3 signaling pathway in UUO mice," Journal of the Medical Association of Thailand, vol. 94, Supplement 7:S1-9, 2011.

[50] A. L. Haas, D. Boscoboinik, D. S. Mojon, M. Böhnke, and A. Azzi, "Vitamin E inhibits proliferation of human Tenon's capsule fibroblasts in vitro," Ophthalmic Research, vol. 28, no. 3, pp. 171-175, 1996.

[51] J. P. Godbout, B. M. Berg, C. Krzyszton, and R. W. Johnson, “ $\alpha$ Tocopherol attenuates NF $\kappa$ B activation and pro-inflammatory cytokine production in brain and improves recovery from lipopolysaccharide- induced sickness behavior," Journal of Neuroimmunology, vol. 169, no. 1-2, pp. 97-105, 2005.

[52] Q. Jiang, X. Yin, M. A. Lil, M. L. Danielson, H. Freiser, and J. Huang, "Long-chain carboxychromanols, metabolites of vitamin E, are potent inhibitors of cyclooxygenases," Proceedings of the National Academy of Sciences of the United States of America, vol. 105, no. 51, pp. 20464-20469, 2008.

[53] A. Fazzio, D. Marilley, and A. Azzi, “The effect of $\alpha$-Tocopherol and $\beta$-tocopherol on proliferation, protein kinase $C$ activity and gene expression in different cell lines., IUBMB Life, vol. 41, no. 1, pp. 93-101, 1997.

[54] E. Kakishita, A. Suehiro, Y. Oura, and K. Nagai, "Inhibitory effect of vitamin $\mathrm{E}$ ( $\alpha$-tocopherol) on spontaneous platelet aggregation in whole blood," Thrombosis Research, vol. 60, no. 6, pp. 489-499, 1990.

[55] J. J. Hu, G. C. Roush, M. Berwick et al., "Effects of dietary supplementation of alpha-tocopherol on plasma glutathione and DNA repair activities," Cancer Epidemiol Biomarkers Prev, vol. 5, no. 4, pp. 263-270, 1996.

[56] P. L. Scardino and W. W. Scott, "THE use of tocopherols in the treatment of peyronie's disease," Annals of the New York Academy of Sciences, vol. 52, no. 3, pp. 390-396, 1949.

[57] C. L. Steinberg, “Tocopherols in treatment of primary fibrositis; including Dupuytren's contracture, periarthritis of the shoulders, and Peyronie's disease," A.M.A. Archives of Surgery, vol. 63, no. 6 , p. $824,1951$.

[58] J. P. Pryor and C. R. Farell, "Controlled clinical trial of vitamin E in Peyronies disease," Prog Reprod Biol Med, vol. 9, pp. 41-45, 1983.

[59] M. R. Safarinejad, S. Y. Hosseini, and A. A. Kolahi, "Comparison of Vitamin E and Propionyl-L-Carnitine, Separately or in Combination, in Patients With Early Chronic Peyronie's Disease: A Double-Blind, Placebo Controlled, Randomized Study," Journal of Urology, vol. 178, no. 4, pp. 1398-1403, 2007. 
[60] A. A. Halal, P. Geavlete, and E. Ceban, "Pharmacological therapy in patients diagnosed with Peyronie's disease.," Journal of medicine and life, vol. 5, no. 2, pp. 192-195, 2012.

[61] V. Favilla, G. I. Russo, and S. Privitera, "Combination of intralesional verapamil and oral antioxidants for Peyronie's disease: a prospective, randomised controlled study," Andrologia, vol. 46, no. 8, pp. 936-942, 2014.

[62] G. Paulis, T. Brancato, R. D’Ascenzo et al., "Efficacy of vitamin $\mathrm{E}$ in the conservative treatment of Peyronie's disease: legend or reality? A controlled study of 70 cases.," Andrology, vol. 1, no. 1, pp. 120-128, 2013.

[63] F. M. Vaz and R. J. A. Wanders, "Carnitine biosynthesis in mammals," Biochemical Journal, vol. 361, no. 3, pp. 417-429, 2002.

[64] I. Gülçin, "Antioxidant and antiradical activities of L-carnitine," Life Sciences, vol. 78, no. 8, pp. 803-811, 2006.

[65] P. Ge, Y. Cui, F. Liu, J. Luan, X. Zhou, and J. Han, "L-carnitine affects osteoblast differentiation in NIH3T3 fibroblasts by the IGF-1/PI3K/Akt signalling pathway," BioScience Trends, vol. 9, no. 1, pp. 42-48, 2015.

[66] B.-J. Lee, J.-S. Lin, Y.-C. Lin, and P.-T. Lin, "Antiinflammatory effects of l-carnitine supplementation $(1000 \mathrm{mg} / \mathrm{d})$ in coronary artery disease patients," Nutrition, vol. 31, no. 3, pp. 475-479, 2015.

[67] A. Koc, T. Ozkan, A. Z. Karabay, A. Sunguroglu, and F. Aktan, "Effect of L-carnitine on the synthesis of nitric oxide in RAW 264.7 murine macrophage cell line," Cell Biochemistry and Function, vol. 29, no. 8, pp. 679-685, 2011.

[68] F. Jiang, Z. Zhang, Y. Zhang, J. Wu, L. Yu, and S. Liu, "L-carnitine ameliorates the liver inflammatory response by regulating carnitine palmitoyltransferase I-dependent PPAR $\gamma$ signaling," Molecular Medicine Reports, vol. 13, no. 2, pp. 1320-1328, 2016.

[69] M. Alvarez De Sotomayor, R. Bueno, C. Pérez-Guerrero, and M. D. Herrera, "Effect of L-carnitine and propionyl-L-carnitine on endothelial function of small mesenteric arteries from SHR," Journal of Vascular Research, vol. 44, no. 5, pp. 354-364, 2007.

[70] S. Benvenga, A. Amato, M. Calvani, and F. Trimarchi, "Effects of carnitine on thyroid hormone action," Annals of the New York Academy of Sciences, vol. 1033, pp. 158-167, 2004.

[71] G. Biagiotti and G. Cavallini, "Acetyl-L-carnitine vs tamoxifen in the oral therapy of Peyronie's disease: A preliminary report," BJU International, vol. 88, no. 1, pp. 63-67, 2001.

[72] G. Cavallini, G. Biagiotti, A. Koverech, and G. Vitali, "Oral propionyl-L-carnitine and intraplaque verapamil in the therapy of advanced and resistant Peyronie's disease," BJU International, vol. 89, no. 9, pp. 895-900, 2002.

[73] J. P. De La Cruz, M. M. Romero, P. Sanchez, and F. Sanchez de la Cuesta, "Antiplatelet effect of pentoxifylline in human whole blood," General Pharmacology, vol. 24, no. 3, pp. 605-609, 1993.

[74] T. W. Costantini, J. Deree, C. Y. Peterson et al., "Pentoxifylline modulates p47phox activation and downregulates neutrophil oxidative burst through PKA-dependent and -independent mechanisms," Immunopharmacology and Immunotoxicology, vol. 32, no. 1, pp. 82-91, 2010.

[75] V. R. Sunil, K. N. Vayas, J. A. Cervelli et al., "Pentoxifylline attenuates nitrogen mustard-induced acute lung injury, oxidative stress and inflammation," Experimental and Molecular Pathology, vol. 97, no. 1, pp. 89-98, 2014.

[76] J. P. Freitas and P. M. Filipe, "Pentoxifylline - A hydroxyl radical scavenger," Biological Trace Element Research, vol. 47, no. 1-3, pp. 307-311, 1995.
[77] G. Lin, A. W. Shindel, L. Banie et al., "Pentoxifylline attenuates transforming growth factor- $\beta 1$-stimulated elastogenesis in human Tunica albuginea-derived fibroblasts part 2: Interference in a TGF- $\beta 1 /$ smad-dependent mechanism and downregulation of AAT1," Journal of Sexual Medicine, vol. 7, no. 5, pp. 1787-1797, 2010.

[78] A. W. Shindel, G. Lin, H. Ning et al., "Pentoxifylline attenuates transforming growth factor- $\beta 1$-stimulated collagen deposition and elastogenesis in human tunica albuginea-derived fibroblasts part 1: impact on extracellular matrix," The Journal of Sexual Medicine, vol. 7, no. 6, pp. 2077-2085, 2010.

[79] Q. Ji, L. Zhang, H. Jia, and J. Xu, "Pentoxifylline inhibits endotoxin-induced NF-kappa B activation and associated production of proinflammatory cytokines," Annals of Clinical \& Laboratory Science, vol. 4, pp. 427-436, 2004.

[80] R. A. Isbrucker and T. C. Peterson, "Platelet-derived growth factor and pentoxifylline modulation of collagen synthesis in myofibroblasts," Toxicology and Applied Pharmacology, vol. 149, no. 1, pp. 120-126, 1998.

[81] J.-M. Anaya and L. R. Espinoza, "Phosphodiesterase inhibitor pentoxifylline: an antiinflammatory/immunomodulatory drug potentially useful in some rheumatic diseases," Journal of Rheumatology, vol. 22, no. 4, pp. 595-599, 1995.

[82] E. G. A. Valente, D. Vernet, M. G. Ferrini, A. Qian, J. Rajfer, and N. F. Gonzalez-Cadavid, "L-Arginine and phosphodiesterase (PDE) inhibitors counteract fibrosis in the Peyronie's fibrotic plaque and related fibroblast cultures," Nitric Oxide - Biology and Chemistry, vol. 9, no. 4, pp. 229-244, 2003.

[83] W. O. Brant, R. C. Dean, and T. F. Lue, "Treatment of Peyronie's disease with oral pentoxifylline," Nature Clinical Practice Urology, vol. 3, no. 2, pp. 111-115, 2006.

[84] J. F. Smith, A. W. Shindel, Y.-C. Huang et al., "Pentoxifylline treatment and penile calcifications in men with Peyronie's disease," Asian Journal of Andrology, vol. 13, no. 2, pp. 322-325, 2011.

[85] M. R. Abern, S. Larsen, and L. A. Levine, "Combination of penile traction, intralesional verapamil, and oral therapies for peyronie's disease," Journal of Sexual Medicine, vol. 9, no. 1, pp. 288-295, 2012.

[86] F. Ciociola and G. M. Colpi, "Peyronie's disease: A triple oxygenant therapy," Archivio Italiano di Urologia e Andrologia, vol. 85, no. 1, pp. 36-40, 2013.

[87] L. Dell'Atti and G. Ughi, "Efficacy of pentoxifylline in Peyronie's disease: clinical case of a young man," Archivio Italiano di Urologia e Andrologia, vol. 86, no. 3, pp. 237-237, 2014.

[88] M. Alizadeh, F. Karimi, and M. R. Fallah, "Evaluation of verapamil efficacy in Peyronie's disease comparing with pentoxifylline," Global journal of health science, vol. 6, no. 7, pp. 23-30, 2014.

[89] G. Paulis, D. Barletta, P. Turchi et al., "Efficacy and safety evaluation of pentoxifylline associated with other antioxidants in medical treatment of Peyronie's disease: a case-control study," Research and Reports in Urology, vol. 8, pp. 1-10, 2015.

[90] B. Frei, M. C. Kim, and B. N. Ames, "Ubiquinol-10 is an effective lipid-soluble antioxidant at physiological concentrations," Proceedings of the National Academy of Sciences of the United States of America, vol. 87, no. 12, pp. 4879-4883, 1990.

[91] H.-J. Jung, E.-H. Park, and C.-J. Lim, "Evaluation of antiangiogenic, anti-inflammatory and antinociceptive activity of coenzyme Q10 in experimental animals," Journal of Pharmacy and Pharmacology, vol. 61, no. 10, pp. 1391-1395, 2009. 
[92] G. López-Lluch, M. P. Barroso, S. F. Martín et al., "Role of plasma membrane coenzyme Q on the regulation of apoptosis," BioFactors, vol. 9, no. 2-4, pp. 171-177, 1999.

[93] C. Szardening-Kirchner, L. Konrad, E. W. Hauck, S. M. Haag, O. Eickelberg, and W. Weidner, "Upregulation of mRNA expression of MCP-1 by TGF- $\beta 1$ in fibroblast cells from Peyronie's disease," World Journal of Urology, vol. 27, no. 1, pp. 123-130, 2009.

[94] M. Ebadi, S. K. Sharma, S. Wanpen, and A. Amornpan, "Coenzyme Q10 inhibits mitochondrial complex-1 down-regulation and nuclear factor-kappa B activation," Journal of Cellular and Molecular Medicine, vol. 8, no. 2, pp. 213-222, 2004.

[95] M. R. Safarinejad, "Safety and efficacy of coenzyme Q 10 supplementation in early chronic Peyronie's disease: A double-blind, placebo-controlled randomized study," International Journal of Impotence Research, vol. 22, no. 5, pp. 298-309, 2010.

[96] M. L. Khalil, "Biological activity of bee propolis in health and disease," Asian Pacific Journal of Cancer Prevention, vol. 7, no. 1, pp. 22-31, 2006.

[97] C. Sun, Z. Wu, Z. Wang, and H. Zhang, "Effect of ethanol/water solvents on phenolic profiles and antioxidant properties of Beijing propolis extracts," Evidence-Based Complementary and Alternative Medicine, vol. 2015, Article ID 595393, 9 pages, 2015.

[98] C. S. Machado, J. B. Mokochinski, T. O. de Lira et al., "Comparative study of chemical composition and biological activity of yellow, green, brown, and red Brazilian propolis," Evidence-Based Complementary and Alternative Medicine, vol. 2016, Article ID 6057650, 11 pages, 2016.

[99] S. Kumazawa, T. Hamasaka, and T. Nakayama, "Antioxidant activity of propolis of various geographic origins," Food Chemistry, vol. 84, no. 3, pp. 329-339, 2004.

[100] S. Huang, C.-P. Zhang, K. Wang, G. Li, and F.-L. Hu, "Recent advances in the chemical composition of propolis," Molecules, vol. 19, no. 12, pp. 19610-19632, 2014.

[101] M. Khalil and S. Sulaiman, "The potential role of honey and its polyphenols in preventing heart disease: a review," African Journal of Traditional, Complementary and Alternative Medicines, vol. 7, no. 4, pp. 315-321, 2010.

[102] A. Russo, R. Longo, and A. Vanella, "Antioxidant activity of propolis: role of caffeic acid phenethyl ester and galangin," Fitoterapia, vol. 73, supplement 1, pp. S21-S29, 2002.

[103] X. Wang, G. Gong, W. Yang, Y. Li, M. Jiang, and L. Li, "Antifibrotic activity of galangin, a novel function evaluated in animal liver fibrosis model," Environmental Toxicology and Pharmacology, vol. 36, no. 2, pp. 288-295, 2013.

[104] Y. C. Jung, M. E. Kim, J. H. Yoon et al., "Anti-inflammatory effects of galangin on lipopolysaccharide-activated macrophages via ERK and NF- $\kappa$ B pathway regulation," Immunopharmacology and Immunotoxicology, vol. 36, no. 6, pp. 426-432, 2014.

[105] D. Ribeiro, M. Freitas, S. M. Tomé, A. M. S. Silva, G. Porto, and E. Fernandes, "Modulation of human neutrophils' oxidative burst by flavonoids," European Journal of Medicinal Chemistry, vol. 67, pp. 280-292, 2013.

[106] A. W. Boots, G. R. M. M. Haenen, and A. Bast, "Health effects of quercetin: from antioxidant to nutraceutical," European Journal of Pharmacology, vol. 585, no. 2-3, pp. 325-337, 2008.

[107] Y.-D. Min, C.-H. Choi, H. Bark et al., "Quercetin inhibits expression of inflammatory cytokines through attenuation of NF- $\kappa$ B and p38 MAPK in HMC-1 human mast cell line," Inflammation Research, vol. 56, no. 5, pp. 210-215, 2007.
[108] G. M. Raso, R. Meli, G. di Carlo, M. Pacilio, and R. di Carlo, "Inhibition of inducible nitric oxide synthase and cyclooxygenase- 2 expression by flavonoids in macrophage J774A.1," Life Sciences, vol. 68, no. 8, pp. 921-931, 2001.

[109] T. Nakamura, M. Matsushima, Y. Hayashi et al., "Attenuation of transforming growth factor- $\beta$-stimulated collagen production in fibroblasts by quercetin-induced heme oxygenase-1," American Journal of Respiratory Cell and Molecular Biology, vol. 44, no. 5, pp. 614-620, 2011.

[110] L. C. Paracatu, C. M. Faria, C. Quinello et al., "Caffeic acid phenethyl ester: consequences of its hydrophobicity in the oxidative functions and cytokine release by leukocytes," Evidence-Based Complementary and Alternative Medicine, vol. 2014, Article ID 793629, 13 pages, 2014.

[111] F. Armutcu, S. Akyol, S. Ustunsoy, and F. F. Turan, "Therapeutic potential of caffeic acid phenethyl ester and its anti-inflammatory and immunomodulatory effects (Review)," Experimental and Therapeutic Medicine, vol. 9, no. 5, pp. 15821588, 2015.

[112] W.-X. Zhao, L. Wang, J.-L. Yang, L.-Z. Li, W.-M. Xu, and T. $\mathrm{Li}$, "Caffeic acid phenethyl ester attenuates pro-inflammatory and fibrogenic phenotypes of LPS-stimulated hepatic stellate cells through the inhibition of NF-kB signaling," International Journal of Molecular Medicine, vol. 33, no. 3, pp. 687-694, 2014.

[113] M. M. Mia and R. A. Bank, "The pro-fibrotic properties of transforming growth factor on human fibroblasts are counteracted by caffeic acid by inhibiting myofibroblast formation and collagen synthesis," Cell and Tissue Research, vol. 363, no. 3, pp. 775-789, 2016.

[114] K. J. Woo, Y.-J. Jeong, H. Inoue, J.-W. Park, and T. K. Kwon, "Chrysin suppresses lipopolysaccharide-induced cyclooxygenase-2 expression through the inhibition of nuclear factor for IL-6 (NF-IL6) DNA-binding activity," FEBS Letters, vol. 579, no. 3, pp. 705-711, 2005.

[115] H. Cho, C.-W. Yun, W.-K. Park et al., "Modulation of the activity of pro-inflammatory enzymes, COX-2 and iNOS, by chrysin derivatives," Pharmacological Research, vol. 49, no. 1, pp. 37-43, 2004.

[116] A. Ahad, A. A. Ganai, M. Mujeeb, and W. A. Siddiqui, "Chrysin, an anti-inflammatory molecule, abrogates renal dysfunction in type 2 diabetic rats," Toxicology and Applied Pharmacology, vol. 279, no. 1, pp. 1-7, 2014.

[117] H.-M. Lo, M.-W. Wu, S.-L. Pan, C.-Y. Peng, P.-H. Wu, and W.B. Wu, "Chrysin restores PDGF-induced inhibition on protein tyrosine phosphatase and reduces PDGF signaling in cultured VSMCs," Journal of Nutritional Biochemistry, vol. 23, no. 6, pp. 667-678, 2012.

[118] Y. Dong, H. Huang, M. Zhao, D. Sun-Waterhouse, L. Lin, and C. Xiao, "Mechanisms underlying the xanthine oxidase inhibitory effects of dietary flavonoids galangin and pinobanksin," Journal of Functional Foods, vol. 24, pp. 26-36, 2016.

[119] A. C. Santos, S. A. Uyemura, J. L. C. Lopes, J. N. Bazon, F. E. Mingatto, and C. Curti, "Effect of naturally occurring flavonoids on lipid peroxidation and membrane permeability transition in mitochondria," Free Radical Biology and Medicine, vol. 24, no. 9, pp. 1455-1461, 1998.

[120] L.-T. Zhou, K.-J. Wang, L. Li, H. Li, and M. Geng, "Pinocembrin inhibits lipopolysaccharide-induced inflammatory mediators production in BV2 microglial cells through suppression of PI3K/Akt/NF- $\kappa$ B pathway," European Journal of Pharmacology, vol. 761, pp. 211-216, 2015. 
[121] K.-S. Chen, M.-D. Shi, C.-S. Chien, and Y.-W. Shih, "Pinocembrin suppresses TGF- $\beta 1$-induced epithelial-mesenchymal transition and metastasis of human Y-79 retinoblastoma cells through inactivating $\alpha \mathrm{v} \beta 3$ integrin/FAK/p38 $\alpha$ signaling pathway," Cell and Bioscience, vol. 4, no. 1, article 41, 2014.

[122] E. Alday, D. Valencia, A. L. Carreño et al., "Apoptotic induction by pinobanksin and some of its ester derivatives from Sonoran propolis in a B-cell lymphoma cell line," Chemico-Biological Interactions, vol. 242, pp. 35-44, 2015.

[123] W.-W. Jung, "Protective effect of apigenin against oxidative stress-induced damage in osteoblastic cells," International Journal of Molecular Medicine, vol. 33, no. 5, pp. 1327-1334, 2014.

[124] R. Landolfi, R. L. Mower, and M. Steiner, "Modification of platelet function and arachidonic acid metabolism by bioflavonoids. Structure-activity relations," Biochemical Pharmacology, vol. 33, no. 9, pp. 1525-1530, 1984.

[125] L. Chen and W. Zhao, "Apigenin protects against bleomycininduced lung fibrosis in rats," Experimental and Therapeutic Medicine, vol. 11, no. 1, pp. 230-234, 2016.

[126] Lemourt O. M., Filgueiras L. E., Rodríguez B. A., González O. E., and Bordonado R., "Clinical evaluation of the use of propoleum in Peyronie's disease," Archivos Españoles de Urología, vol. 51, no. 2, pp. 171-176, 1998.

[127] Lemourt O. M., Rodríguez B. A., Puente G. M., Vega G. C., Navarro C. M., and Pérez M. A., "Peyronie's disease and propoleum," Archivos Espanoles de Urologia, vol. 56, no. 7, pp. 805-813, 2003.

[128] Lemourt O. M., Rodríguez B. A., Bordonado R. R., González O. E., and Molina C. F., "Dose study with propoleum in Peyronie's disease," Archivos Espanoles de Urologia, vol. 56, no. 7, pp. 814819, 2003.

[129] Lemourt O. M., Fragas V. R., Bordonado R. R., J. L. Santana, González O. E., and A. Merino, "Peyronie's disease. Evaluation of three therapeutic methodologies: Propoleum, laser and propoleum-laser," Archivos Espanoles de Urologia, vol. 58, no. 9, pp. 931-935, 2005.

[130] G. Paulis, R. D’Ascenzo, P. Nupieri et al., "Effectiveness of antioxidants (propolis, blueberry, vitamin E) associated with verapamil in the medical management of Peyronie's disease: A study of 151 cases," International Journal of Andrology, vol. 35, no. 4, pp. 521-527, 2012.

[131] G. Paulis, G. Cavallini, T. Brancato, and R. Alvaro, "Peironimevplus ${ }^{\circledR}$ in the treatment of chronic inflammation of tunica albuginea (peyronie's disease). Results of a controlled study," Inflammation and Allergy - Drug Targets, vol. 12, no. 1, pp. 61-67, 2013.

[132] G. Paulis, G. Cavallini, G. De Giorgio, S. Quattrocchi, T. Brancato, and R. Alvaro, "Long-term multimodal therapy (Verapamil associated with propolis, blueberry, vitamin E and local Diclofenac) on patients with peyronie's disease (chronic inflammation of the tunica albuginea). results of a controlled study," Inflammation and Allergy - Drug Targets, vol. 12, no. 6, pp. 403-409, 2013.

[133] D. Burdulis, L. Ivanauskas, V. Dirse, S. Kazlauskas, and A. Razukas, "Study of diversity of anthocyanin composition in bilberry (Vaccinium myrtillus L.) fruits.," Medicina (Kaunas, Lithuania), vol. 43, no. 12, pp. 971-977, 2007.

[134] N. P. Seeram, "Berry fruits for cancer prevention: current status and future prospects," Journal of Agricultural and Food Chemistry, vol. 56, no. 3, pp. 630-635, 2008.
[135] A. Fleuriet, "The Main Phenolics of Fruit," in Fruit Phenolics, J. J. Macheix, A. Fleuriet, and J. Billot, Eds., pp. 1-99, CRC Press, Inc, Boca Raton, Fla, USA, 1990.

[136] M. M. Rahman, T. Ichiyanagi, T. Komiyama, Y. Hatano, and T. Konishi, "Superoxide radical- and peroxynitrite-scavenging activity of anthocyanins; structure-activity relationship and their synergism," Free Radical Research, vol. 40, no. 9, pp. 9931002, 2006.

[137] T. Ichiyanagi, Y. Hatano, S. Matsuo, and T. Konishi, "Simultaneous comparison of relative reactivities of twelve major anthocyanins in bilberry towards reactive nitrogen species," Chemical and Pharmaceutical Bulletin, vol. 52, no. 11, pp. 13121315, 2004.

[138] S. Roth, M. R. Spalinger, C. Gottier et al., "Bilberry-derived anthocyanins modulate cytokine expression in the intestine of patients with ulcerative colitis," PLoS ONE, vol. 11, no. 5, Article ID e0154817, 2016.

[139] D.-X. Hou, T. Yanagita, T. Uto, S. Masuzaki, and M. Fujii, "Anthocyanidins inhibit cyclooxygenase-2 expression in LPS-evoked macrophages: Structure-activity relationship and molecular mechanisms involved," Biochemical Pharmacology, vol. 70, no. 3, pp. 417-425, 2005.

[140] M. C. Lazzè, R. Pizzala, P. Perucca et al., "Anthocyanidins decrease endothelin-1 production and increase endothelial nitric oxide synthase in human endothelial cells," Molecular Nutrition and Food Research, vol. 50, no. 1, pp. 44-51, 2006.

[141] N. Xia, A. Pautz, U. Wollscheid, G. Reifenberg, U. Förstermann, and H. Li, "Artichoke, cynarin and cyanidin downregulate the expression of inducible nitric oxide synthase in human coronary smooth muscle cells," Molecules, vol. 19, no. 3, pp. 3654-3668, 2014.

[142] C. Artaria, R. Pace, G. Maramaldi, and G. Appendino, "Different brands of bilberry extract: a comparison of selected components," NUTRAfoods, vol. 6, no. 4, pp. 13-18, 2007.

[143] I. Gouni-Berthold and A. Sachinidis, "Molecular mechanisms explaining the preventive effects of catechins on the development of proliferative diseases," Current Pharmaceutical Design, vol. 10, no. 11, pp. 1261-1271, 2004.

[144] T. J. Bivalacqua, H. C. Champion, S. Leungwattanakij et al., "Evaluation of nitric oxide synthase and arginase in the induction of a Peyronie's-like condition in the rat," Journal of Andrology, vol. 22, no. 3, pp. 497-506, 2001.

[145] M. G. Ferrini, D. Vernet, T. R. Magee et al., "Antifibrotic role of inducible nitric oxide synthase," Nitric Oxide, vol. 6, no. 3, pp. 283-294, 2002.

[146] M. Bentz, C. Zaouter, Q. Shi et al., "Inhibition of inducible nitric oxide synthase prevents lipid peroxidation in osteoarthritic chondrocytes," Journal of Cellular Biochemistry, vol. 113, no. 7, pp. 2256-2267, 2012.

[147] J.-P. Pelletier, D. Jovanovic, J. C. Fernandes et al., "Reduced progression of experimental osteoarthritis in vivo by selective inhibition of inducible nitric oxide synthase," Arthritis and Rheumatism, vol. 41, no. 7, pp. 1275-1286, 1998. 


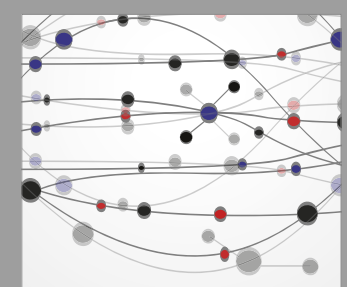

The Scientific World Journal
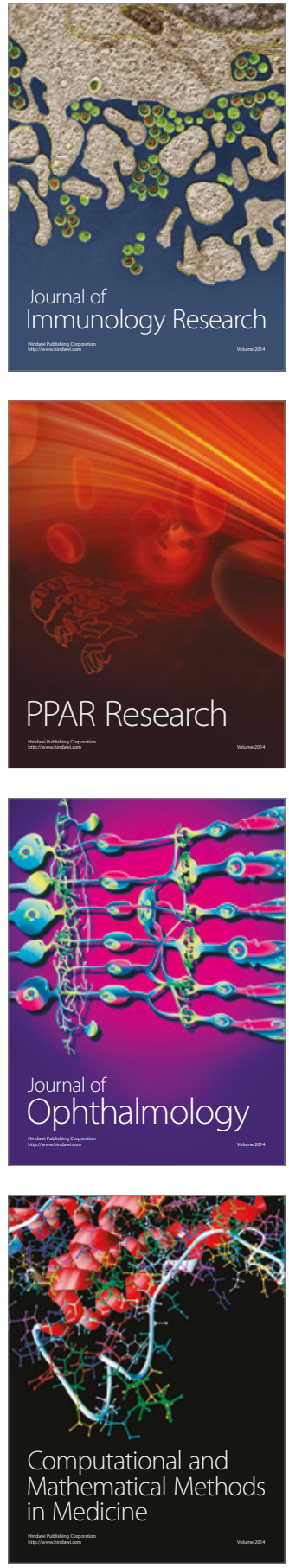

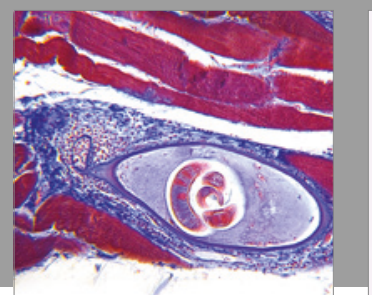

Gastroenterology Research and Practice
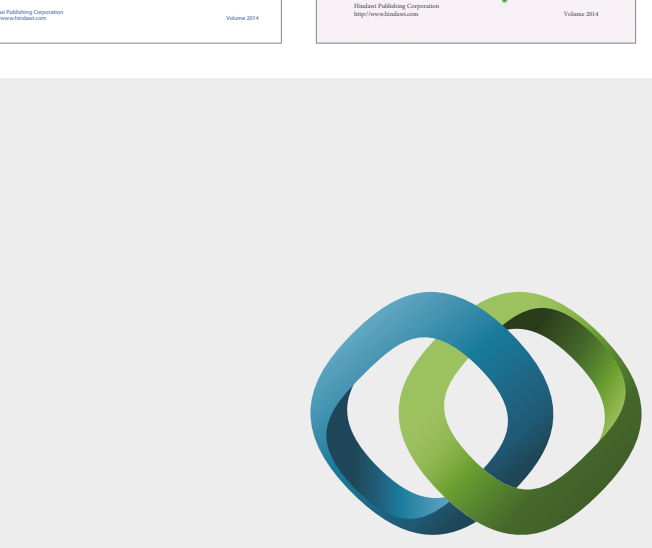

\section{Hindawi}

Submit your manuscripts at

https://www.hindawi.com
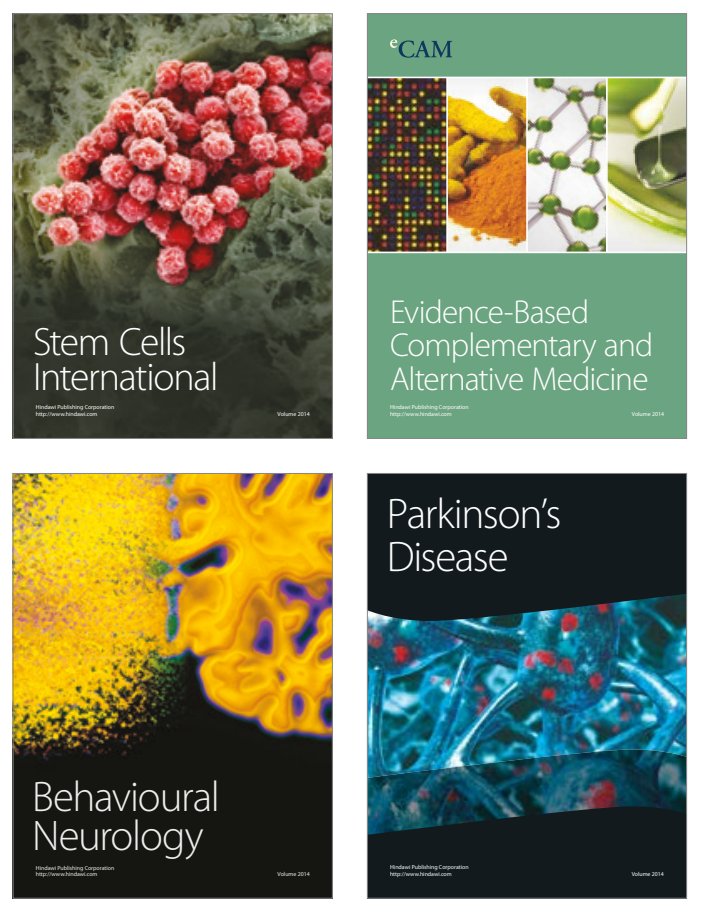
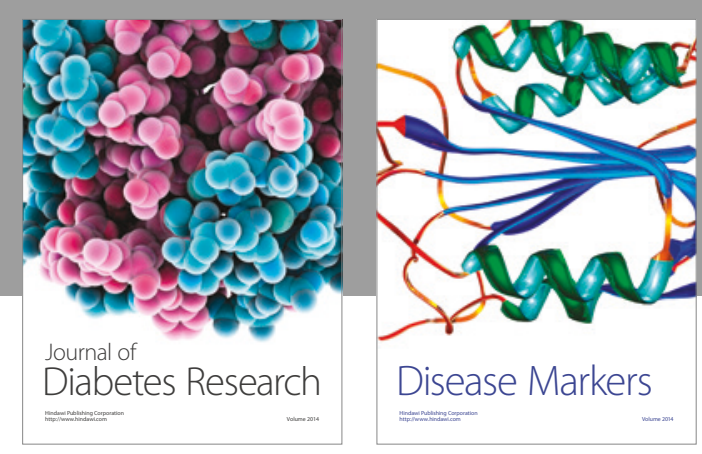

Disease Markers
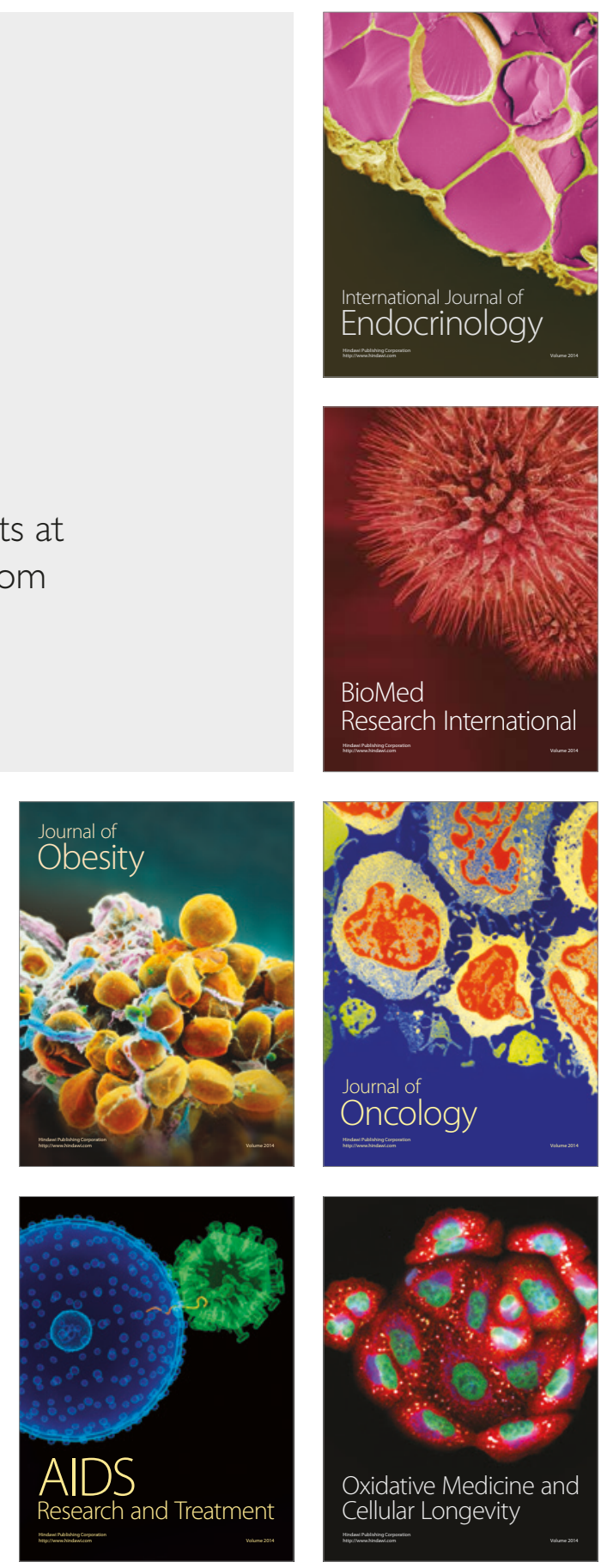